\title{
DIVERSIDADE DE ANUROS DE SERAPILHEIRA EM FRAGMENTOS DE FLORESTA ATLÂNTICA E PLANTIOS DE Eucalyptus saligna NO MUNICÍPIO DE PILAR DO SUL, SP
}

\author{
Sílvia HELENA de OLIVEIRA
}

Dissertação apresentada à Escola Superior de Agricultura "Luiz de Queiroz", Universidade de São Paulo, para obtenção do titulo de Mestre em Ecologia Agroecossistemas.

\author{
PIR A C I C A B A \\ Estado de São Paulo - Brasil
}

Abril - 2004 


\title{
DIVERSIDADE DE ANUROS DE SERAPILHEIRA EM FRAGMENTOS DE FLORESTA ATLÂNTICA E PLANTIOS DE Eucalyptus saligna NO MUNICÍPIO DE PILAR DO SUL, SP
}

\author{
Sílvia Helena de Oliveira \\ Ecóloga \\ Orientador: Prof. Dr. CÉLIO FERNANDO B. HADDAD
}

Dissertação apresentada à Escola Superior de Agricultura "Luiz de Queiroz", Universidade de São Paulo, para obtenção do titulo de Mestre em Ecologia, de Agroecossistemas.

PIR A C I C A B A

Estado de São Paulo - Brasil

Abril - 2004 


\section{Dados internacionais de Catalogação na Publicação (CIP) Divisão de Biblioteca e Documentação - CAMPUS "LUIZ DE QUEIROZ"/USP}

Oliveira, Sílvia Helena

Diversidade de anuros de serapilheira em fragmentos de Floresta Atlântica e plantios de Eucalyptus saligna no Município de Pilar do Sul, SP / Sílvia Helena de Oliveira. -- Piracicaba, 2004 60 p.: il.

Dissertação (mestrado) -- Escola Superior de Agricultura Luiz de Queiroz, 1995 Bibliografia.

1. Anura 2. Biodiversidade 3. Ecologia 4. Eucalipto 5. Floresta 6. Matéria orgânica do solo I. Título

CDD 597.8

"Permitida a cópia total ou parcial deste documento, desde que citada a fonte - O autor" 
Dedico:

aos meus pais (Lourdes e Silvio), com todo amor e gratidão pela vida proporcionada; ao Ricardo, pelo amor e por se fazer tão presente. 


\section{AGRADECIMENTOS}

Meus mais sinceros agradecimentos:

ao Professor Célio Haddad pela orientação, discussões, sugestões e correções na dissertação;

à Claudinha pela deleitosa amizade e ajuda em todos os momentos do trabalho, desde a elaboração do projeto até o final da dissertação;

ao Jovercino pelo companheirismo prestado em campo, não perdendo o humor mesmo quando se desentedia com "Bastião" na chuva;

ao "Bastião" que me conduziu em todos os campos;

ao Benedito Amaral (Bene) pela imensurável paciência e auxílio nas questões estatísticas;

ao Ricardo Sawaya pelas diversas idéias propostas e ajuda dos tratamentos estatíscos;

à EUCATEX S/A pelo apoio logístico e financeiro disponibilizados durante a realização deste trabalho;

à todos funcionários da EUCATEX que em algum momento colaborou com esse trabalho;

ao Gustavo Betini por esclarecer diversas dúvidas;

ao amigo Fábio (Trupico) por ceder informações e fotos adquiridas durante o seu estudo realizado com Puma concolor; 
ao Prof. Luciano Verdade pelo apoio, sugestões e correções na dissertação;

à Carla Gheler sempre tão disposta à ajudar;

ao André (Pardal) por ceder fotos e registros de espécies que enriqueceram o inventário de anuros;

à $D$. Dita e o Sr. Eudóxio pelas inúmera hospedagem;

ao Ricardo por toda paciência, apoio, amor e carinhos fazendo-o sempre tão especial;

aos meus pais e meus irmãos, Francis e Junior, pela amizade e carinho, amor, apoio......e tudo que me faz mais feliz;

aos amigos de Piracicaba pela agradável convivência. 


\section{SUMÁRIO}

Página

LISTA DE FIGURAS........................................................................ viii

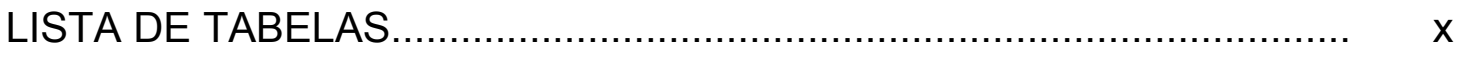

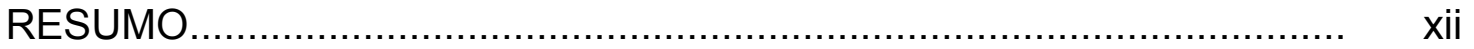

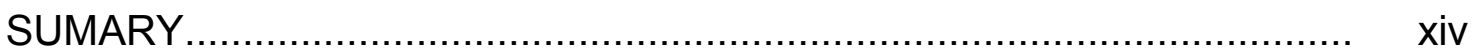

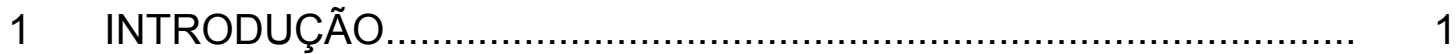

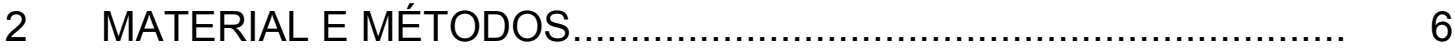

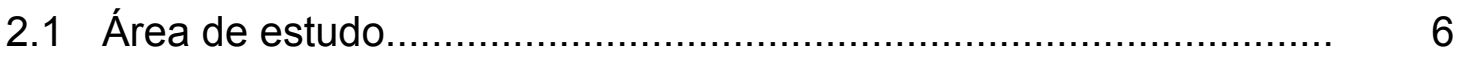

2.2 Coleta de dados............................................................. 8

2.3 Variáveis ambientais amostradas................................................... 11

2.4 Análise dos resultados.................................................................. 12

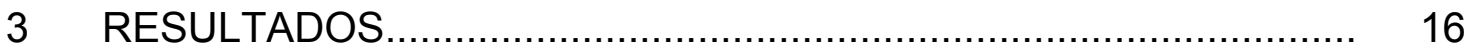

3.1 Espécies inventariadas na Fazenda João XXIII............................... 16

3.2 Riqueza e abundância relativa da comunidade de anuros de serapilheira.

3.3 Riqueza, diversidade e abundância relativa das espécies de anuros de serapilheira em floresta contínua, fragmentos circundados por plantios de E. saligna e plantios de E. saligna

3.4 Relação entre a diversidade da anurofauna de serapilheira e as varáveis ambientais.

3.5 A influência do período na captura de anuros de serapilheira........... 35

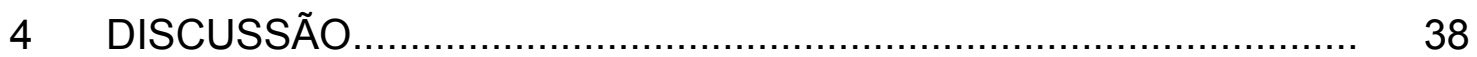

4.1 A comunidade de anfíbios anuros da Fazenda João ....................... 38

4.2 Anuros de serapilheira na Fazenda João XXIII................................ 40 
4.3 Considerações finais............................................................ 43

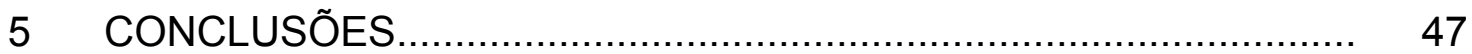

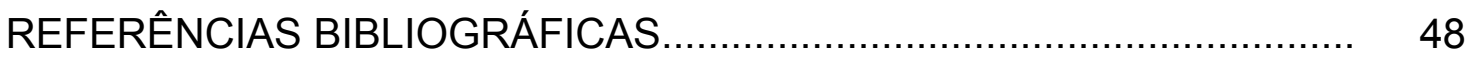




\section{LISTA DE FIGURAS}

Página

1 Localização e caracterização da Fazenda João XXIII, Município de Pilar do Sul, SP (adaptado de Pires, 1994 e Höhe, 2001). Os números 1, 2 e 3 indicam as transeções amostradas na floresta contínua, 4 e 5 nos plantios de Eucalyptus. saligna e 6, 7 e 8 nos fragmentos circundados por plantios de E. saligna.

2 Pluviosidade mensal em milímetros para o período de fevereiro de 2000 a janeiro de 2001 e a média dos últimos dez anos...................

3 Linha de armadilhas de interceptação e queda com cerca-guia em fragmento circundado por $E$. saligna $(A)$; detalhe da cerca-guia (B, C).

4 Espécies de anuros de serapilheira na Fazenda João XXIII, no Município de Pilar do Sul, SP

5 Curva de rarefação de espécies para as 288 amostras nos ambientes estudados: floresta contínua, fragmentos circundados por plantios de E. saligna e plantios de E. saligna.

6 Capturas totais e abundancia relativa (\%) das diferentes espécies de anuros verificadas na Fazenda João XXIII entre fevereiro de 2000 e janeiro de 2001.

7 Curva de rarefação de espécies para as 72 amostras em plantios de E. saligna, 108 amostras em floresta contínua e 108 amostras em fragmentos circundados por plantios de E. saligna.

8 Distribuição das abundâncias relativas de anuros coletados nos 
três ambientes amostrados entre fevereiro de 2000 e janeiro de 2001. $\mathrm{FC}=$ Floresta contínua, $\mathrm{FR}=$ Fragmentos circundados por plantios de E. saligna e EC = Plantios de E. saligna..........................

9 Diagrama de ordenação ("triplot" ou Axis 3) dos diferentes tratamentos e das espécies ao longo dos $1^{\circ}$ e $2^{\circ}$ eixos da Análise de Correspondência Canônica (ACC), geradas a partir de cinco varáveis ambientais

10 Número de indivíduos das diferentes espécies observadas durante o verão e o inverno na floresta contínua, $F C(A)$; nos fragmentos circundados por plantios de E.saligna, FR (B) e plantios de $E$. saligna, EC (C). Número total de captura em cada ambiente (D)...... 


\section{LISTA DE TABELAS}

Página

1 Espécies de anfíbios anuros inventariadas na Fazenda João XXIII, município de Pilar do Sul - SP, no período de fevereiro de 2000 a janeiro de 2001

2 Espécies de anuros capturadas nas transeções amostrados em floresta contínua, fragmentos circundados por plantios de eucaliptos e plantios de eucaliptos entre fevereiro de 2000 e janeiro de 2001, na Fazenda João XXIII

3 Abundância absoluta, riqueza, estimador de riqueza Jackknife (Ŝ) dominância (de Simpson), eqüitabilidade e diversidade (de Shannon-Wiener) dos anuros coletados nos três ambientes amostrados entre fevereiro de 2000 e janeiro de 2001, na Fazenda João XXIII, Pilar do Sul, SP. FC = Floresta contínua, $\mathrm{FR}=$ Fragmentos circundados por plantios de $E$. saligna e $\mathrm{EC}=$ Plantios de E. saligna

4 Capturas totais, primeiras capturas e índice de recaptura em plantios de E. saligna, na Fazenda João XXIII, Município de Pilar do Sul.

5 Capturas totais, primeiras capturas e índice de recaptura em fragmentos circundados por plantios de E. saligna, na Fazenda João XXIII, Município de Pilar do Sul.

6 Capturas totais, primeiras capturas e índice de recaptura em floresta contínua, na Fazenda João XXIII, Município de Pilar do Sul. 
7 Resumo de resultados obtidos em trabalhos realizados em 46 Floresta Atlântica do Estado de São Paulo.................................... 


\title{
DIVERSIDADE DE ANUROS DE SERAPILHEIRA EM FRAGMENTOS DE FLORESTA ATLÂNTICA E PLANTIOS DE Eucalyptus saligna NO MUNICÍPIO DE PILAR DO SUL, SP
}

\author{
Autora: SÍLVIA HELENA DE OLIVEIRA \\ Orientador: Prof. Dr. CÉLIO FERNANDO B. HADDAD
}

\section{RESUMO}

A Floresta Atlântica é considerada um dos mais importantes conjuntos de ecossistemas e apesar de ser caracterizada pela alta diversidade de espécies e elevado grau de endemismo, os conhecimentos acumulados sobre a sua fauna ainda são incipientes. Com a anurofauna poucos estudos enfocam a distribuição, os padrões ecológicos e a utilização de ambientes alterados por ação antrópica. O Estado de São Paulo apresenta uma extensa área de plantios de Eucalyptus spp. em áreas anteriormente ocupadas por Floresta Atlântica; no entanto, informações de como os anuros de serapilheira utilizam esses ambientes ainda não foram abordadas nessas regiões. O presente estudo foi desenvolvido em um mosaico de remanescentes de Floresta Atlântica e plantios de Eucalyptus saligna na Fazenda João XXIII, localizada no Município de Pilar do Sul - SP, objetivando caracterizar a riqueza, a composição específica e a diversidade de anuros de serapilheira existente na área, incluindo os plantios. Para a coleta dos anuros utilizou-se armadilhas de 
interceptação e queda com cercas-guias distribuídas em três ambientes floresta contínua, fragmentos circundados por plantios de $E$. saligna e os próprios plantios. Durante os 12 meses de coleta, com um esforço amostral de 1728 armadilhas-dia, foram registradas 23 espécies na área de estudo, das quais seis foram consideradas capturas acidentais; sendo analisados os dados referentes a 1454 capturas. A taxocenose de anuros de serapilheira na Fazenda João XXIII é composta de pelo menos quatro espécies relativamente comuns e nove espécies raras. As espécies com maior abundância relativa em ambientes de floresta nativa foram Crossodactylus caramaschii, Eleutherodactylus guentheri, Bufo crucifer e Adenomera marmorata. Nos plantios de E. saligna, B. crucifer foi responsável por $60,85 \%$ da abundância relativa de espécies. Um total de 18 espécies foi estimado para a localidade; o método utilizado amostrou aproximadamente $94,4 \%$ da riqueza estimada de anuros de serapilheira. No entanto, poucas espécies de lagartos e serpentes foram registradas, indicando que o método é apropriado para a amostragem de anuros de serapilheira, mas deve ser combinado a outros métodos para melhor caracterização da riqueza total de espécies da herpetofauna de serapilheira. A diversidade de espécies foi semelhante nos dois ambientes de floresta nativa e menor nos plantios de E. saligna. Os resultados obtidos, aliados ao atual contexto de fragmentação e degradação da Floresta Atlântica, demonstram que os plantios de E. saligna na Fazenda João XXIII, se devidamente manejados, podem ser localmente importantes para a conservação de anuros de serapilheira, visto que o ambiente parece ser utilizado como hábitat por muitas das espécies registradas em ambientes florestais, ainda que em menor abundância. 


\title{
DIVERSITY OF LITTER FROGS IN ATLANTIC FOREST FRAGMENTS AND EUCAL YPTUS SALIGNA PLANTATIONS ON PILAR DO SUL, SP
}

\author{
Author: SÍLVIA HELENA DE OLIVEIRA \\ Adviser: Prof. Dr. CÉLIO FERNANDO B. HADDAD
}

\section{SUMMARY}

The Atlantic Forest is considered one of the most important sets of ecosystems being characterized by the high diversity of species and high degree of endemisms. In spite of the high diversity of anuran amphibians, information on the distribution, ecological patterns, and use of altered environments are incipient. The State of São Paulo presents an extensive area of Eucalyptus spp. plantations. In areas previously covered by the Atlantic Forest. However, information of the way litter frogs still use these environments have not been obtained in these areas. The present study was developed in a mosaic of Atlantic Forest remnants and Eucalyptus saligna plantations in the Fazenda João XXIII, located in the Municipality of Pilar do Sul - São Paulo State. The goal of this study was to survey the anuran species of litter to verify its richness and diversity in the forest fragments and in the E. saligna plantations. For the collection of the litter frogs were used pitfall with drift-fences distributed in three environments: continuous forest, fragments surrounded by $E$. saligna and $E$. saligna plantations. During the 12 months of work, with a sampling effort of 1728 
trap-day, in the studied site 23 species were registered, of wich six were considered accidental captures, being analyzed 1454 captures. The litter frog assemblage at Fazenda João XXIII has at least four relatively common species and nine rare species. The species with higher relative abundance in environments of native forest were Crossodactylus caramaschii, Eleutherodactylus guentheri, Bufo crucifer, and Adenomera marmorata. In the E. saligna plantations, B. crucifer was responsible for $60.85 \%$ of the relative abundance of species. A total of 18 species was estimated for the locality, the used method showed approximately $94.4 \%$ of the estimated richness of litter frogs. However, few species of lizards and snakes were registered, indicating that the method is appropriate for the sampling of litter frogs, but must be combined to other methods for a better characterization of the total herpetofauna. The species diversity was similar in the two environments of native forest and lesser in the $E$. saligna plantations. The results obtained in the present context of fragmentation and degradation of the Atlantic Forest demonstrate that the E. saligna plantations in the Fazenda João XXIII, if duly handled, represent an important role in the local conservation of litter anuran species, because most of these species use this environment as habitat, although in lesser abundance that in the environments of native forest. 


\section{INTRODUÇÃo}

Como a maioria das florestas tropicais, ecossistemas ricos em número de espécies, a Floresta Atlântica se encontra reduzida a fragmentos esparsos e isolados, muitos dos quais com menos de 100 ha e bastante perturbados (Turner \& Corlett, 1996; Fonseca, 1985). Embora ocupem áreas íngremes de difícil acesso e matas ciliares, estes são regularmente explorados pela caça predatória e extração ilegal de produtos florestais. Em 500 anos de intensa pressão antrópica, destacando-se a retirada de madeira, agricultura, criação de gado e construção de cidades (Morellato \& Haddad, 2000) a Floresta Atlântica foi reduzida, segundo o Ministério do Meio Ambiente (BRASIL, 1999), a 7,6\% da sua extensão original. Hoje vivem 100 milhões de pessoas em áreas anteriormente ocupadas por esta floresta (SOS Mata Atlântica, 1999) e, mesmo com os constantes processos de desmatamentos sofridos, ainda é possível encontrar regiões que preservam grande parte de suas características faunísticas e florísticas intactas (Guix et al., 1992).

Embora considerada um dos mais importantes conjuntos de ecossistemas do planeta, com uma alta diversidade de espécies e elevado grau de endemismo, é um dos mais ameaçados, sendo uma das prioridades em conservação no mundo (Terborgh, 1992; EMBRAPA, 1994; Viana et al., 1997). A falta de estudos de médio e longo prazo e levantamentos faunísticos em diferentes regiões, junto com a velocidade de destruição dos ambientes naturais restantes, faz com que a fauna da Floresta Atlântica seja pouco conhecida (Haddad, 1991). 
A paisagem que envolve a maioria dos fragmentos de Floresta Atlântica no Estado de São Paulo é um grande mosaico formado por fragmentos de floresta secundária e áreas cultivadas. Em termos teóricos, os efeitos da fragmentação sobre as comunidades naturais e a sua biodiversidade já foram explicitados (Wilcox \& Murphy, 1985; Shafer, 1990; Saunders et al., 1991; Terborgh, 1992; Brown \& Brown, 1992; Noss \& Csuti, 1994). No entanto, no caso das florestas tropicais, a única conseqüência deste processo, bem estabelecida empiricamente, é a perda de espécies nos remanescentes em relação à floresta contínua (Turner, 1996).

A teoria da biogeografia de ilhas (MacArthur \& Wilson, 1967) embasou as primeiras abordagens da estrutura e dinâmica de hábitats naturais fragmentados. Porém, este modelo não leva em consideração fatores importantes em ecossistemas continentais, tal como a matriz em que estão inseridos os remanescentes e a permeabilidade da mesma às diferentes espécies de uma comunidade (Noss \& Csuti, 1994). Taylor et al. (1993) enfatizaram a necessidade de uma conectividade entre as diferentes formações vegetais existentes em uma paisagem em mosaico.

A persistência de algumas espécies em áreas fragmentadas pode estar relacionada com a capacidade de dispersão através da matriz (Laurance, 1991a, Laurance \& Bierregaard, 1997; Gascon, et al., 1999). A vegetação que circunda o fragmento, favorecendo ou impedindo esta conectividade, é de extrema importância para a sobrevivência de uma meta-população em paisagens fragmentadas (Metzger \& Decamps, 1997). Alguns autores têm sugerido que anfíbios podem ser particularmente sensíveis ao efeito da fragmentação de hábitat (Wyman 1990; Wake, 1991; Bradford et al., 1993; Blaustein et al., 1994). Por mostrarem grande fidelidade aos locais que habitam (Kleeberger \& Werner, 1982; Sinsch, 1990) e muitos deles terem pouca capacidade de dispersão (Harris 1975; Sinch, 1990), mesmo um pequeno grau de fragmentação poderia efetivamente isolar populações de anfíbios. 
Dois conceitos distintos, riqueza específica (número de espécies) e abundância relativa de espécies, estão inclusos no termo diversidade biológica (Krebs, 1989). A diversidade de espécies de uma comunidade ou taxocenose pode ser medida pela riqueza específica e pela dominância da espécie mais abundante expressa em porcentagem. Os princípios de rarefação de espécie e riqueza estão sendo cada vez mais incorporados nas medidas de padrão de diversidade de espécie e nos conceitos de ecologia de comunidade e biogeografia, principalmente para inventariar comunidades ricas em espécies e documentar a perda de diversidade de espécies com a destruição de hábitats (Gotelli \& Colwell, 2001).

Os trabalhos realizados no Brasil sobre distribuição espacial, temporal, ocorrência e abundância de anfíbios, em sua maioria são descritivos das estruturas das comunidades, estudos estes fundamentais para o embasamento de modelos teóricos e trabalhos experimentais (Andrade, 1994). Apenas a partir de informações básicas sobre os ecossistemas, é possível definir estratégias de conservação. O estudo da biodiversidade, seja sobre composição e distribuição de espécies ou ecologia de comunidades, está entre os objetivos básicos da Estratégia Global para a Biodiversidade (Wilson, 1992). A região neotropical é a que possui a maior riqueza específica de anfíbios e répteis, sendo ideal para o estudo dos padrões de diversidade destes grupos (Cadle \& Patton, 1988; Duellman, 1988; Heyer 1988; Martins, 1994). Estudos de cunho ecológico e/ou quantitativo sobre a anurofauna nas regiões serranas do sudeste do Brasil, compreendidas no domínio morfoclimático da Floresta Atlântica (AB'Saber, 1977), popularmente denominada Mata Atlântica, que são particularmente ricas em espécies de anfíbios, são praticamente inexistentes (Haddad \& Sazima, 1992).

Alguns autores têm chamado a atenção para a perda de espécies relacionada com a destruição quase total da Floresta Atlântica e o alto número que ela possui de espécies endêmicas especializadas para o ambiente de floresta (Miranda \& Mattos, 1992; Morellato \& Haddad, 2000). Pelo menos 
metade das espécies de anfíbios de florestas requer hábitats especializados para a reprodução e estes habitats não estão homogeneamente e abundantemente distribuídos através das florestas (Zimmerman \& Bierregaard, 1986). Entretanto, se as exigências de hábitats forem compreendidas, áreas que contém hábitats críticos poderiam ser preservadas e as chances de manter populações de anfíbios florestais seriam amplamente melhoradas (Zimmerman \& Bogart, 1988).

Pouco se sabe sobre os fatores que influenciam a diversidade da herpetofauna de serapilheira das florestas tropicais. Alguns fatores físicos podem ter influência na densidade, diversidade e/ou biomassa dessas comunidades (Heinen, 1992); entre esses, a umidade, a profundidade da serapilheira e a altitude (Scott 1976; Fauth et al., 1989; Sawaya, 1999). Scott (1976), comparando a herpetofauna de serapilheira de localidades da América Central e sudeste da Ásia, sugeriu que o aumento do número de meses secos, com pluviosidade menor que $100 \mathrm{~mm}$, pode influenciar no número de espécies. Camadas de matéria orgânica morta e em decomposição depositadas sobre o chão das florestas proporcionam abrigo, alimento e locais de acasalamento e de ovoposição para a herpetofauna (Scott, 1976) que, quando associada à serapilheira em florestas tropicais caracteriza-se pela alta riqueza de espécies (Heyer et al., 1990; Zimmerman \& Rodrigues, 1990; Vitt \& Caldwell, 1994). Estudos com esta fauna têm ressaltado os padrões de abundância e distribuição entre tipos de vegetação e regiões geográficas (Brown \& Alcala, 1961; Heyer, 1967; Lloyd et al., 1968; Heyer \& Berven, 1973; Scott, 1976; Inger, 1980,a, b), em gradientes altitudinais e mudanças sazonais em diversidade (Brown \& Alcala, 1961; Scott, 1976; Giaretta et al., 1999; Sawaya, 1999).

No Brasil são poucas as informações de como os anuros se comportam em hábitats fragmentados. Tocher et al. (1997), estudando o efeito da fragmentação em comunidade de anuros na Amazônia, observaram que a riqueza esta positivamente relacionada com o tamanho da área. Dixo (2001), estudando cabruca (plantações de cacau sob mata rarefeita) no sul da Bahia, 
encontrou uma riqueza de 13 espécies, cinco a menos que nas áreas de vegetação nativa, embora a diversidade entre os ambientes estudados não tenha sido diferentes. Os remanescentes de Floresta Atlântica estão envolvidos por diferentes usos da terra, sendo que na região da Serra de Paranapiacaba uma extensa área de plantios de Eucalyptus spp. está em contato direto com os remanescentes florestais.

Os plantios de Eucalyptus spp. se iniciaram no Brasil de forma experimental no ano de 1909 (Sampaio, 1961), concentrando-se principalmente nas regiões Sul e Sudeste, que nessa época já apresentavam pouca cobertura florestal natural (Lima, 1996). No ano de 1965, com a criação do programa federal de incentivos fiscais, iniciaram-se os grandes plantios; extensas áreas de Floresta Atlântica foram substituídas por reflorestamentos com espécies exóticas. É comum que estes plantios estejam em contato direto com remanescentes florestais ou envolvendo fragmentos. A cobertura total de reflorestamentos com Eucalyptus spp. no Estado de São Paulo em 1992 era de $812.523,32$ ha, o equivalente a 3,27 \% de sua área (Governo do Estado de São Paulo, 1993). Mesmo com esta extensa área, nenhum estudo enfoca o uso destes reflorestamentos por espécies de anfíbios no Estado de São Paulo.

Neste contexto de profunda alteração dos ambientes naturais, aliada à escassez de informações básicas sobre a anurofauna de serapilheira, este trabalho tem como objetivo observar como este grupo comporta-se nos diferentes ambientes estudados na Fazenda João XXIII, Município de Pilar do Sul, Estado de São Paulo, utilizando como parâmetros da comunidade amostrada as seguintes características:

1) a riqueza específica;

2) a abundância relativa e a dominância;

3) a relação com variáveis ambientais. 


\section{MATERIAL E MÉTODOS}

\section{1 Área de estudo}

O presente estudo foi desenvolvido na Fazenda João XXIII, de propriedade da Eucatex S/A Indústria e Comércio, situada no Município de Pilar

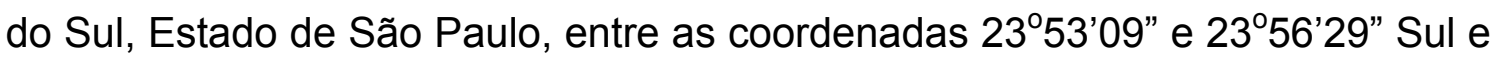
$47^{\circ} 42^{\prime} 30^{\prime \prime}$ e $47^{\circ} 40^{\prime} 08^{\prime \prime}$ Oeste (Figura 1). A área possui 2.486 ha, sendo 1.318 de plantios de Eucalyptus saligna intercalados por 440 ha de remanescentes de Floresta Atlântica e matas ciliares, e um fragmento de 611 ha ao sul da fazenda. Este fragmento é adjacente ao maior contínuo florestal do Estado de São Paulo, formado pela APA da Serra de Tapiraí, Parque Estadual de Carlos Botelho e o Parque Estadual de Intervales. O relevo apresenta-se ondulado, com declividade acentuada e altitudes variando de 650 a 980 metros.

O Município de Pilar do Sul está inserido na Bacia Hidrográfica do Alto Paranapanema e, de acordo Pfeifer et al. (1986), os solos são classificados como Latossolos Vermelho-amarelo, reconhecidos como argilosos, profundos, pouco ácidos, coesos e de coloração vermelha-amarela relativamente homogênea, ocorrendo em altitudes superiores a $600 \mathrm{~m}$, preferencialmente entre $700 \mathrm{~m}$ e $800 \mathrm{~m}$.

O clima é definido por Köeppen como subtropical úmido - Cfa. A temperatura média do mês mais quente para o Município de Pilar do Sul é de $22,4^{\circ} \mathrm{C}$ e do mês mais frio é de $15,4^{\circ} \mathrm{C}$. A precipitação média anual entre fevereiro de 1990 e janeiro de 2000 foi de $1533,45 \mathrm{~mm}$, entre fevereiro de 2000 a janeiro de 2001 foi de $1381,10 \mathrm{~mm}$ com a menor precipitação mensal de 
$0,00 \mathrm{~mm}$ e a maior de $311 \mathrm{~mm}$. Na Figura 2 percebe-se que os meses de fevereiro a junho, outubro e janeiro tiveram uma pluviosidade mensal abaixo da média observada nos últimos 10 anos e os meses de setembro e dezembro mantiveram-se acima da média.

A Floresta Tropical Atlântica cobre principalmente elevações baixas a médias ( $\leq 1000 \mathrm{~m}$ de elevação) da cadeia montanhosa oriental que corre ao longo do litoral, do sul ao nordeste do Brasil, com clima quente e úmido sem uma estação seca (Oliveira \& Filho, 2000; Morellato et al. 2000, In: Morellato and Haddad, 2000). Segundo Leitão Filho (1982), a Fazenda João XXIII pertence à região fitoecológica ou fitossociológica da Floresta Ombrófila ou Floresta Pluvial, também chamada de Floresta Latifoliada Perenifólia ou Floresta Atlântica. Os ambientes da formação Montana da Floresta Ombrófila ocupam os altos dos planaltos e serras nas faixas de altitude de 500 a $1500 \mathrm{~m}$ (Veloso, 1991).

O período de maior interferência nos remanescentes florestais da Fazenda João XXIII foi até o final dos anos 60 , com a extração parcial das madeiras nativas de maior porte para a produção de carvão. Na década de 1970 a área teve uso agrícola e a partir do início da década de 1980 as atividades restringiram-se ao plantio e extração de E. saligna. Atualmente, a fazenda apresenta-se como um mosaico de plantios de $E$. saligna e fragmentos de Floresta Atlântica em transição do estágio sucessional secundário inicial para o secundário tardio, tendo grandes extensões de florestas vizinhas que funcionam como fonte dispersora de espécies vegetais nativas no sub-bosque dos talhões. As principais perturbações na área de floresta se devem a invasões por caçadores e, sobretudo, a excursões esporádicas de palmiteiros.

Segundo Albuquerque (1999), em levantamento fitossociológico preliminar realizado na Fazenda João XXIII, a maior porção de mata do local se mostra uma área de transição entre Mata Ombrófila Densa e Mata Estacional Semidecídua, predominando representantes vegetais da primeira formação com árvores emergentes que, fora raras exceções, não ultrapassam 25 metros. A 
mesma autora encontrou 123 espécies arbóreas neste local, pertencentes a 37 famílias e 87 gêneros, verificando uma maior riqueza específica nas famílias Fabaceae (17), Myrtaceae e Melastomataceae (10), Annonaceae e Arecaceae (7), Euphorbiaceae e Sapindaceae (6) e Lauraceae, Meliaceae e Rubiaceae (5). As matas ciliares de grotas e riachos apresentam dominância de samambaiaçu (Pteridophyta) e de espécies das famílias Musaceae, Zingiberaceae e Cannaceae. Devido à localização da área, no alto da Serra de Paranapiacaba, é possível encontrar um grande número de espécies representantes de Floresta Semidecídua, mas os representantes de Floresta Tropical Atlântica estão em maior número.

Os plantios de E. saligna apresentam-se em vários estágios de crescimento, desde recém cortados a talhões com mais de sete anos esperando o corte. O sub-bosque é formado principalmente por piperáceas como: Piper aduncun e Piper amalago, sendo dominado em algumas porções por pteridófitas no estrato herbáceo. Os talhões estudados encontravam-se com seis anos e possuíam uma densa regeneração no sub-bosque.

\subsection{Coleta de dados}

Os ambientes a serem estudados, assim como as réplicas aplicadas (Figura 1), foram determinados principalmente pela predominância em termos de área ocupada e logística como acesso às localidades e disponibilidade de material. Foram escolhidos como representativos i) floresta contínua ( $\mathrm{N}=3$ transeções), ii) fragmentos circundados por plantios de Eucalyptus saligna ( $\mathrm{N}=$ 3 transeções) e iii) plantios de $E$. saligna ( $\mathrm{N}=2$ transeções). As altitudes nos locais amostrados variaram de $750 \mathrm{~m}$ à $980 \mathrm{~m}$.

Os anuros foram coletados através de armadilhas de interceptação e queda com cerca-guia - pitfall traps with drift fences - (Corn, 1994; Greenberg,

\footnotetext{
${ }^{1}$ ALBUQUERQUE, G.B. Levantamento florístico e fitossociológico das reservas naturais da EUCATEX/SA. Pilar do Sul, 1999. 80p. (Relatório técnico não publicado)
} 
Neary, \& Harris, 1994; Webb, 1999; Cechin \& Martins, 2000). Em cada transeção amostrada foram instaladas três estações de armadilhas distribuídas em linha, sendo cada estação composta por dois baldes de $80 \mathrm{~cm}$ de altura e $38 \mathrm{~cm}$ de diâmetro, com aproximadamente 200 litros, e um balde de $30 \mathrm{~cm}$ de altura e $26 \mathrm{~cm}$ de diâmetro com aproximadamente 30 litros, intercalando-os. Os baldes foram conectados por 10 metros de cerca-guia, com $90 \mathrm{~cm}$ de altura e $20 \mathrm{~cm}$ enterrada no solo; esta cerca também foi colocada nas extremidades dos baldes resultando em estações de 40 metros (Figura 3).

As coletas de anuros foram realizadas no período de fevereiro de 2000 a janeiro de 2001, quando os baldes eram abertos por seis dias/mês, sendo vistoriados todos os dias. Os animais capturados eram identificados e marcados com o corte de falange pelo sistema de A. Marlof (1953, In: Donnelly et. al.1994). Os espécimes coletados foram mortos e fixados em formol a $10 \%$ e conservados em álcool a $70 \%$. O material coletado foi depositado na Coleção Célio F. B. Haddad (CFBH), Departamento de Zoologia da Universidade Estadual Paulista, Campus de Rio Claro, São Paulo, Brasil. 


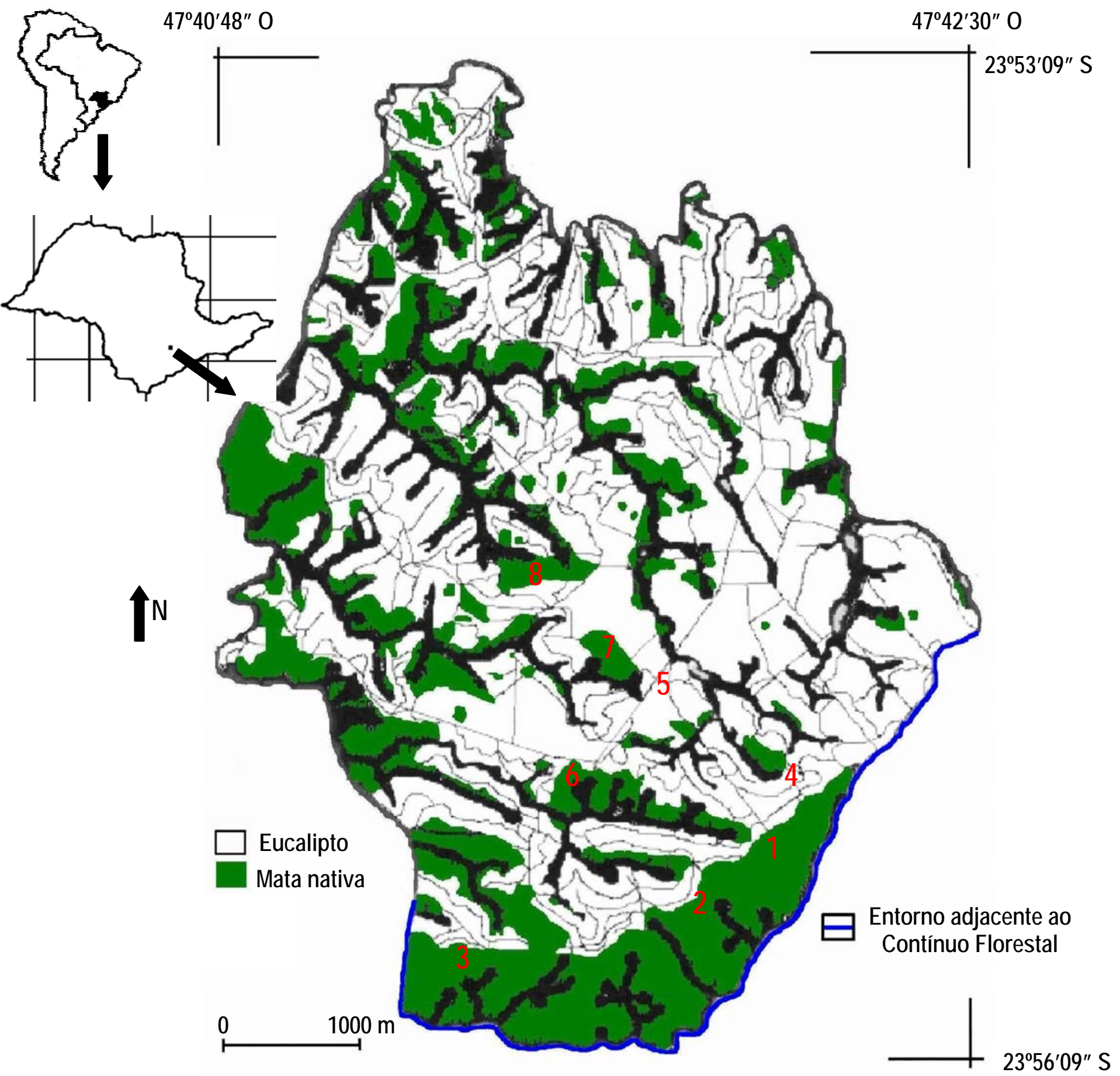

Figura 1 - Localização e caracterização da Fazenda João XXIII, Município de Pilar do Sul, SP (adaptado de Pires, 1994 e Höhe, 2001). Os números 1,2 e 3 indicam as transeções amostradas na floresta contínua, 4 e 5 nos plantios de Eucalyptus saligna e 6, 7 e 8 nos fragmentos circundados por plantios de E. saligna 


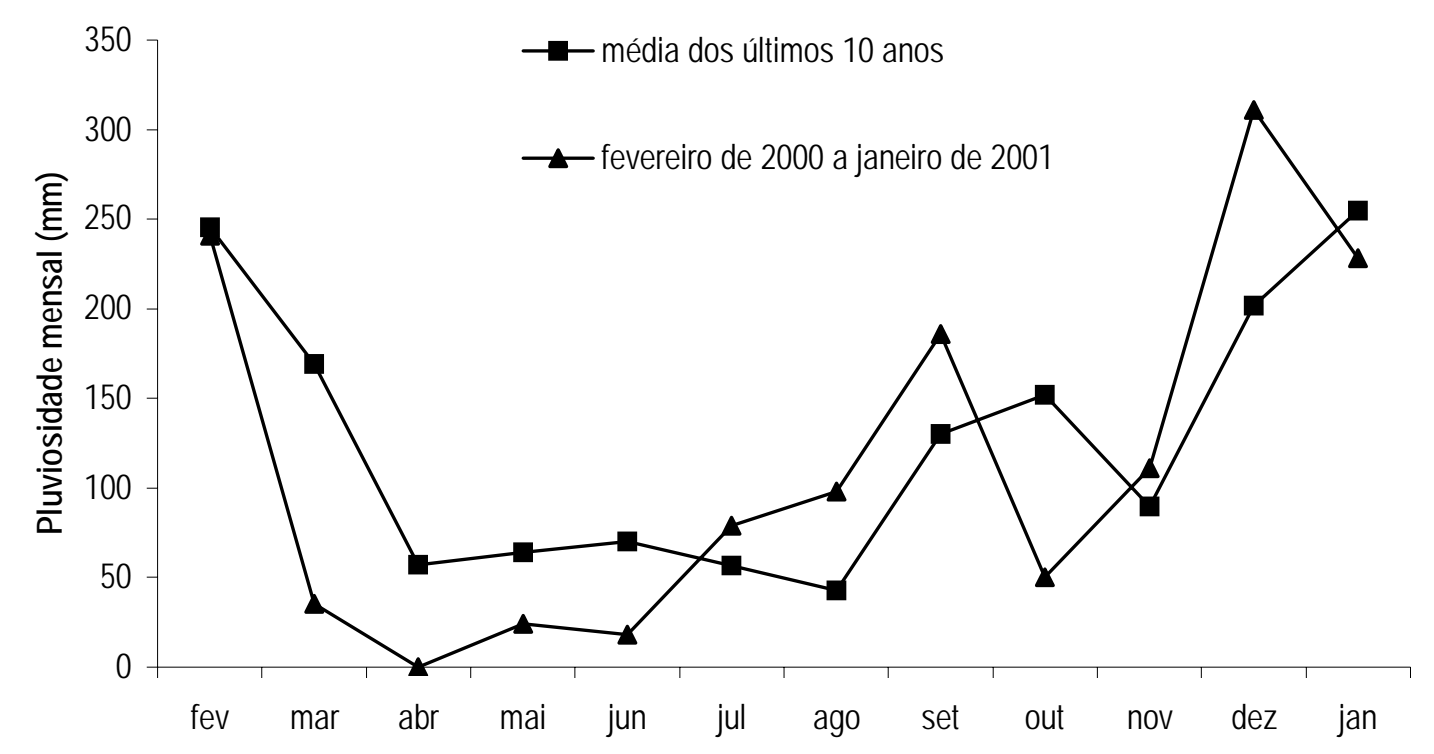

Figura 2 - Pluviosidade mensal, em milímetros, para o período de fevereiro de 2000 a janeiro de 2001 e a média dos últimos 10 anos

\subsection{Variáveis ambientais amostradas}

Para documentar a complexidade estrutural dos três ambientes estudados foram utilizados os dados ambientais de Silva (2001), onde foram estabelecidas três parcelas de $10 \times 10 \mathrm{~m}$, próximas às armadilhas, em cada transeção utilizada para coleta dos anuros, totalizando $2400 \mathrm{~m}^{2}$. Em cada parcela anotou-se morfoespécie, altura e CAP (circunferência à altura do peito) de todas as árvores com CAP maior que $15 \mathrm{~cm}$. Dentro de cada parcela estabeleceu-se sub-parcelas de $5 \times 5 \mathrm{~m}$, onde foram amostradas todas as espécies com CAP menor que $15 \mathrm{~cm}$ e altura no mínimo de $1,5 \mathrm{~m}$, totalizando $1200 \mathrm{~m}^{2}$.

Com a utilização de um densitômetro, foram realizadas 16 medidas por parcela da obstrução de luz no dossel e da presença de cobertura herbácea. 
Nas parcelas estabelecidas nas trilhas em plantios de $E$. saligna, adaptou-se a metodologia de transeções em losango sugerida por Stumpf (1993), para evitar amostragem seguindo as linhas de plantio. Nos mesmos pontos foi medida a altura da serapilheira com o auxílio de uma régua.

As características da estrutura de hábitat coletadas nas 24 parcelas foram:

- altura da serapilheira $(\mathrm{cm})$,

- cobertura do dossel (\%),

- cobertura herbácea $(\%)$,

- número de morfoespécies do dossel (CAP $>15 \mathrm{~cm})$,

- diâmetro médio das árvores com CAP > $15 \mathrm{~cm}$,

- número de morfoespécies no sub-bosque (altura > 1,5 m),

- diâmetro médio dos arbustos (altura > 1,5 m),

- média da altura das árvores pertencentes ao dossel, em metros,

- média de altura do sub-bosque,

- número de indivíduos do dossel,

- número de indivíduos no sub-bosque $>1,5 \mathrm{~m}$.

\subsection{Análise dos resultados}

Para a análise dos dados foram consideradas apenas as espécies de anuros de serapilheira capturadas nas oito transeções entre fevereiro de 2000 a janeiro de 2001, não sendo considerada a espécie Hylodes sp. e os hilídeos Aplastodiscus perviridis, Hyla faber, Hyla sp., Phyllomedusa distincta e P. tetraploidea.

O número total de capturas foi calculado pela soma das primeiras capturas com as recapturas subseqüentes. O esforço amostral foi obtido através da multiplicação do número de armadilhas por dias de coleta, visto que as mesmas se mantiveram abertas durante todo o período de coleta. $O$ sucesso de captura foi obtido multiplicando o total de capturas por 100 e dividindo pelo 
esforço de captura (armadilhas-dia). Para a obtenção da abundância relativa, o número de capturas de uma determinada espécie foi dividido pelo total de capturas obtidas no ambiente amostrado.

A curva de rarefação de espécies foi utilizada com o intuito de apurar a representatividade das amostras. Para a sua realização utilizou-se o programa "EstimateS" (Colwell, 1997), com os dados ordenados em amostras (Gotelli \& Colwell, 2001), baseada na média de 1000 curvas geradas aleatorizando a ordem das amostras espaciais e temporais, somando 288 amostras em 24 pontos de coletas em 12 meses. Assim, cada ponto da curva corresponde à média das 1.000 aleatorizações e está associado a um desvio-padrão.

Para verificar se houve estabilidade em todos os ambientes, foi gerada uma curva de rarefação de espécies para cada ambiente. Para estimar a riqueza específica nos ambientes amostrados e em cada um deles, através do número de espécies encontradas, foi escolhido o estimador de riqueza baseado no método "Jackknife" (Heltshe and Forrester, 1983). Esta estimativa foi calculada com o uso do programa Richness, version 5.1 (Krebs, 1998).

A dominância de Simpson e a diversidade e eqüitabilidade de Shannon foram calculadas através do programa "MVSP" (Kovach, 1999). Para averiguar a homogeneidade das amostras de anuros de serapilheira nos ambientes estudados utilizou-se o teste de Kruskal-Wallis One Way, considerando como variáveis dependentes a abundância, riqueza, dominância, diversidade e eqüitabilidade. Subseqüentemente aplicou-se o teste de Dunn para verificar quais pares de tratamento se diferenciavam; os resultados foram considerados significativos com $p<0,01$.

Para verificar se os dados apresentavam sazonalidade também foi utilizado o teste de Kruskal-Wallis onde foram comparadas abundância, riqueza, dominância, diversidade e eqüitabilidade entre as estações do ano - primavera, verão, outono e inverno. Depois de constatada a diferença o teste de Dunn mostrou quais as estações poderiam ser agrupadas; os resultados foram considerados significativos com $p<0,01$. $O$ mesmo procedimento foi utilizado 
para averiguar possíveis diferenças entre os pontos de coleta na borda e interior dos fragmentos estudados.

A relação entre as variáveis ambientais e a diversidade da anurofauna de serapilheira foram verificadas com a Análise de Correspondência Canônica (ACC), com o programa PC-ORD (Mccune \& Mefford, 1997). Esse método permite a análise de dados ambientais e biológicos conjuntamente e a escolha das varáveis ambientais que melhor explicam o padrão de distribuíção das espécies. Para a construção da matriz de dados biológicos (24 linhas e 17 colunas) foram considerados os 24 pontos de coletas e as 17 espécies que ocorreram nesses pontos. Para a matriz de dados ambientais utilizou-se 11 variáveis ambientais medidas para cada ponto na transeção. A relação de cada uma das varáveis ambientais com a matriz de dados biológicos foi verificada pelo teste de Monte Carlo (Manly, 1991), com 1000 permutações. Para a ordenação da ACC foram consideradas as variáveis significativas segundo este teste $(p<0,05)$. Aplicou-se posteriormente a correção de Bonferroni para múltiplas comparações ( $\alpha=0,004 ; 11$ comparações).

$O$ índice de recaptura das espécies para cada ambiente amostrado foi calculado dividindo-se o número de capturas totais pelo número das primeiras capturas, indivíduos marcados (Stallings, 1989 e 1991). 



Figura 3 - Linha de armadilhas de interceptação e queda com cerca-guia em fragmento circundado por $E$. saligna (A); detalhes da cerca-guia $(B, C)$ 


\section{RESULTADOS}

\subsection{Espécies inventariadas na Fazenda João XXIII}

No período de fevereiro de 2000 a janeiro de 2001 foram inventariadas na área de estudo 45 espécies de anfíbios anuros pertencentes a cinco famílias (Tabela 1).

\subsection{Riqueza e abundância relativa da comunidade de anuros de serapilheira}

Durante 12 meses de coleta, de fevereiro de 2000 a janeiro de 2001, obtivemos na área de estudo um total de 1463 capturas, sendo 1410 indivíduos coletados e 53 recapturas, distribuídas em 23 espécies e 15 gêneros pertencentes às famílias Bufonidae, Leptodactylidae, Hylidae e Mycrohylidae (Tabela 2, Figura 4). A ocorrência de um híbrido triplóide de Phyllomedusa indica a presença das duas espécies parentais $P$. distincta $(2 n=26)$ e $P$. tetraploidea $(4 n=52)$. As espécies da família Hylidae não foram consideradas na análise de dados porque possuem discos adesivos e capacidade escansória; portanto, escapariam dos baldes das armadilhas de interceptação e queda. $O$ gênero Hylodes está normalmente associado a cursos d'água, sendo também obtido em capturas acidentais. Como este levantamento esteve concentrado na captura de espécies de serapilheira, serão consideradas no tratamento dos dados 17 espécies e 1454 indivíduos.

A curva de rarefação de espécies atingiu a assíntota, o que indica que talvez todas as espécies de anuros de serapilheira no local foram registradas 
(Figura 5). O estimador de riqueza escolhido, "Jackknife", indica que aproximadamente 18 espécies $(18,3 \pm 1,33)$ de serapilheira ocorrem na Fazenda João XXIII (Tabela 3).

Entre as espécies mais abundantes no levantamento total da Fazenda João XXIII, Bufo crucifer e Crossodactylus caramaschii aparecem como dominantes, correspondendo a 44,09\% dos indivíduos coletados, seguidas por Eleutherodactylus guentheri e Adenomera marmorata, que somadas com as anteriores representam $73,18 \%$ dos indivíduos amostrados. Posteriormente, encontram-se seis espécies que representam $24,07 \%$ do total de indivíduos e, por último, seis espécies com abundância relativa menor que $1 \%$ cada, que se comportam claramente como espécies raras, perfazendo os $2,75 \%$ restante da comunidade de anuros de serapilheira nos ambientes amostrados (Figura 6). 
Tabela 1. Espécies de anfíbios anuros inventariadas na Fazenda João XXIII, município de Pilar do Sul - SP, no período de fevereiro de 2000 a janeiro de 2001

\section{Espécies}

\section{BUFONIDAE}

Bufo crucifer Wied-Neuwied, 1821

Bufo ictericus Spix, 1824

Dendrophryniscus brevipollicatus Jiménez de la Espada, 1871 "1870" * CENTRONELIDAE

Hyalinobatrachium cf. eurygnathum (A. Lutz, 1925) *

HYLIDAE

Aplastodiscus perviridis A. Lutz, 1950

Hyla albopunctata Spix, 1824

Hyla albosignata A. Lutz and B. Lutz, 1938

Hyla bischoffi Boulenger, 1887

Hyla circumdata (Cope, 1871) *

Hyla faber Wied-Neuwied, 1821

Hyla hylax Heyer, 1985

Hyla microps Peters, 1872

Hyla minuta Peters, 1872

Hyla prasina Burmeister, 1856

Hyla pardalis Spix, 1824

Hyla sanborni Schimidt, 1944*

Hyla sp.1 (gr. polytaenia)

Hyla sp.2

Hyla sp.3 (gr. semiguttata)

Phyllomedusa distincta B. Lutz, 1950 
Tabela 1. Espécies de anfíbios anuros inventariadas na Fazenda João XXIII, município de Pilar do Sul - SP, no período de fevereiro de 2000 a janeiro de 2001

\section{Espécies}

\section{HYLIDAE}

Phyllomedusa tetraploidea Pombal \& Haddad, 1992

Scinax cf. alter (B. Lutz, 1973) *

Scinax fuscovarius (A. Lutz, 1925)

Scinax perereca (Pombal, Haddad, and Kasahara, 1995) *

Scinax rizibilis (Bokermann, 1964) *

Scinax sp. (gr. ruber) *

LEPTODACTYLIDAE

Adenomera marmorata Steindachner, 1867

Crossodactylus caramaschii Bastos \& Pombal, 1995

Cycloramphus acangatan Verdade \& Rodrigues, 2003

Leptodactylus fuscus (Schneider, 1799) *

Leptodactylus ocellatus (Linnaeus, 1758)

Eleutherodactylus binotatus (Spix, 1824)

Eleutherodactylus cf. parvus (Girard, 1853)

Eleutherodactylus guentheri (Steindachner, 1864)

Eleutherodactylus sp.

Hylodes sp. (gr. heyeri)

Macrogenioglottus alipioi Carvalho, 1946

Paratelmatobius sp. (gr. cardosoi)

Physalaemus cuvieri Fitzinger, 1826

Physalaemus olfersii (Lichtenstein and Martens, 1856)

Physalaemus sp.

Proceratophrys boiei (Wied-Neuwied, 1824) 
Tabela 1. Espécies de anfíbios anuros inventariadas na Fazenda João XXIII, município de Pilar do Sul - SP, no período de fevereiro de 2000 a janeiro de 2001

\section{Espécies}

\section{LEPTODACTYLIDAE}

Proceratophrys cf. melanopogon (Miranda-Ribeiro, 1926)

MYCROHYLIDAE

Chiasmocleis leucosticta (Boulenger, 1888)

Myersiella microps (Duméril and Bibron, 1841)

* As espécies marcadas foram registradas durante o estudo conduzido por A.P. Antunes (2003) e cedidas para este levantamento. 
Tabela 2. Espécies de anuros capturadas nas transeções amostrados em floresta contínua, fragmentos circundados por plantios de eucaliptos e plantios de eucaliptos entre fevereiro de 2000 e janeiro de 2001, na Fazenda João XXIII

\begin{tabular}{|c|c|c|c|c|c|c|c|c|c|}
\hline & \multicolumn{8}{|c|}{ Ambientes } & \multirow{3}{*}{ Total } \\
\hline & \multicolumn{3}{|c|}{ Floresta contínua } & \multicolumn{3}{|c|}{ Fragmentos } & \multicolumn{2}{|c|}{ Eucalipto } & \\
\hline & $\mathrm{FC} 1$ & $\mathrm{FC} 2$ & FC3 & FRG1 & FR2 & FR3 & EC1 & EC2 & \\
\hline \multicolumn{10}{|l|}{ Bufonidae } \\
\hline Bufo crucifer & 93 & 29 & 5 & 6 & 33 & 1 & 122 & 35 & 324 \\
\hline Bufo ictericus & 1 & & 1 & 3 & & & & 1 & 6 \\
\hline \multicolumn{10}{|l|}{ Hylidae } \\
\hline Aplastodiscus perviridis & & & & & & 1 & 1 & & 2 \\
\hline Hyla faber & & & 1 & & & & & & 1 \\
\hline Hyla sp. & & 1 & & & 1 & & 1 & & 3 \\
\hline Phyllomedusa (híbrida) & & & & & & & & 1 & 1 \\
\hline \multicolumn{10}{|l|}{ Leptodactylidae } \\
\hline Adenomera marmorata & 6 & 35 & 25 & 14 & 42 & 39 & 6 & 9 & 176 \\
\hline Crossodactylus caramaschii & 32 & 94 & 38 & 93 & 8 & 43 & 6 & 3 & 317 \\
\hline Cycloramphus acangatan & 13 & 16 & 16 & 10 & & 5 & 1 & & 61 \\
\hline Eleutherodactylus binotatus & 6 & 5 & 6 & 8 & 4 & 4 & 3 & 8 & 44 \\
\hline Eleutherodactylus cf. parvus & 1 & 2 & 2 & 1 & & 3 & & & 9 \\
\hline Eleutherodactylus guentheri & 40 & 48 & 41 & 45 & 31 & 41 & 1 & & 247 \\
\hline Eleutherodactylus sp. & & 1 & 2 & & & & & & 3 \\
\hline Hylodes sp. & & & 2 & & & & & & 2 \\
\hline Macrogenioglottus alipioi & & & 1 & & & & & & 1 \\
\hline Paratelmatobius sp. & & 2 & 2 & 1 & 1 & 1 & & & 7 \\
\hline Physalaemus cuvieri & 1 & & & 2 & 9 & 4 & 3 & 34 & 53 \\
\hline Physalaemus olfersii & 7 & 1 & 8 & 1 & 6 & 2 & 3 & 1 & 29 \\
\hline Physalaemus sp. & & & 1 & & 2 & 2 & 1 & 9 & 15 \\
\hline Proceratophrys boiei & 14 & 7 & 16 & 44 & 16 & 14 & 6 & 1 & 118 \\
\hline \multicolumn{10}{|l|}{ Mycrohylidae } \\
\hline Chiasmocleis leucosticta & 2 & 1 & 3 & & 2 & 5 & & 1 & 14 \\
\hline Myersiella microps & 9 & 6 & 10 & 2 & & 2 & & 1 & 30 \\
\hline Total & 225 & 248 & 180 & 230 & 155 & 167 & 154 & 104 & 1463 \\
\hline
\end{tabular}



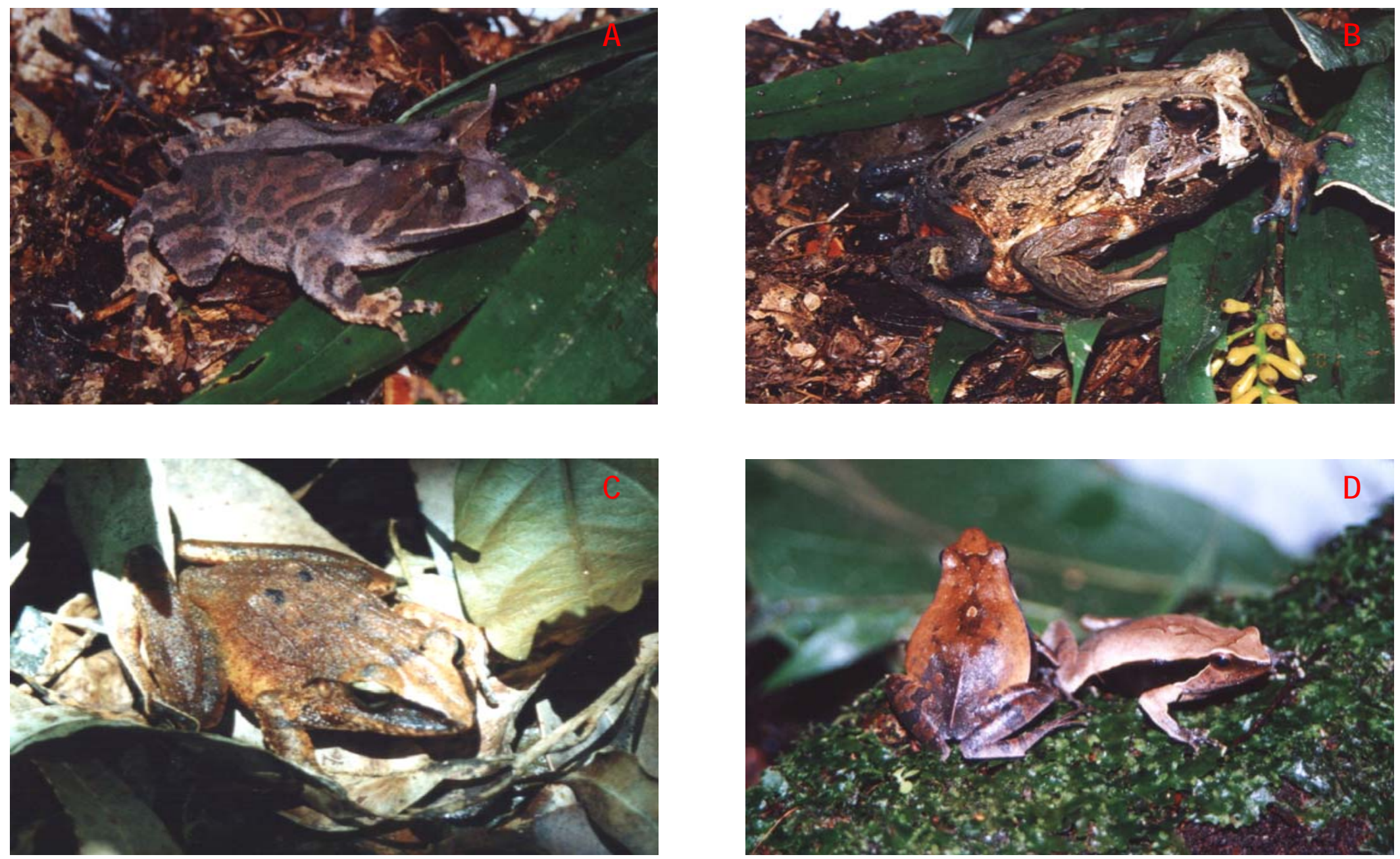

Figura 4 - Espécies de anuros de serapilheira na Fazenda João XXIII, no Município de Pilar do Sul, SP. A Proceratophrys boiei; B - Macrogenioglottus alipioi; C - Eleutherodactylus binotatus; D - Physalaemus olfersii 

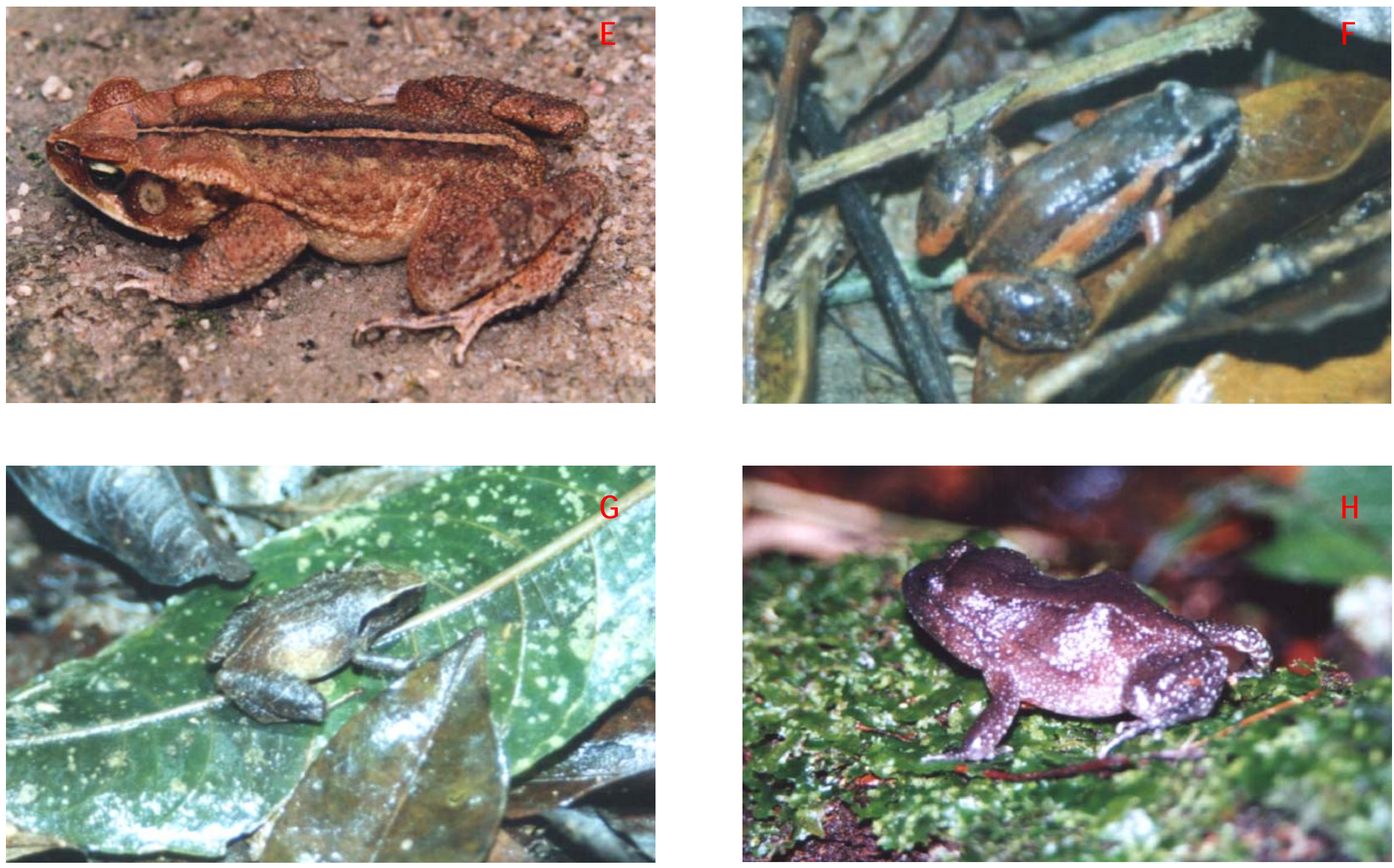

Figura 4 - E - Bufo crucifer; F - Adenomera marmorata; G - Physalaemus sp.; H - Cycloramphus acangatan 

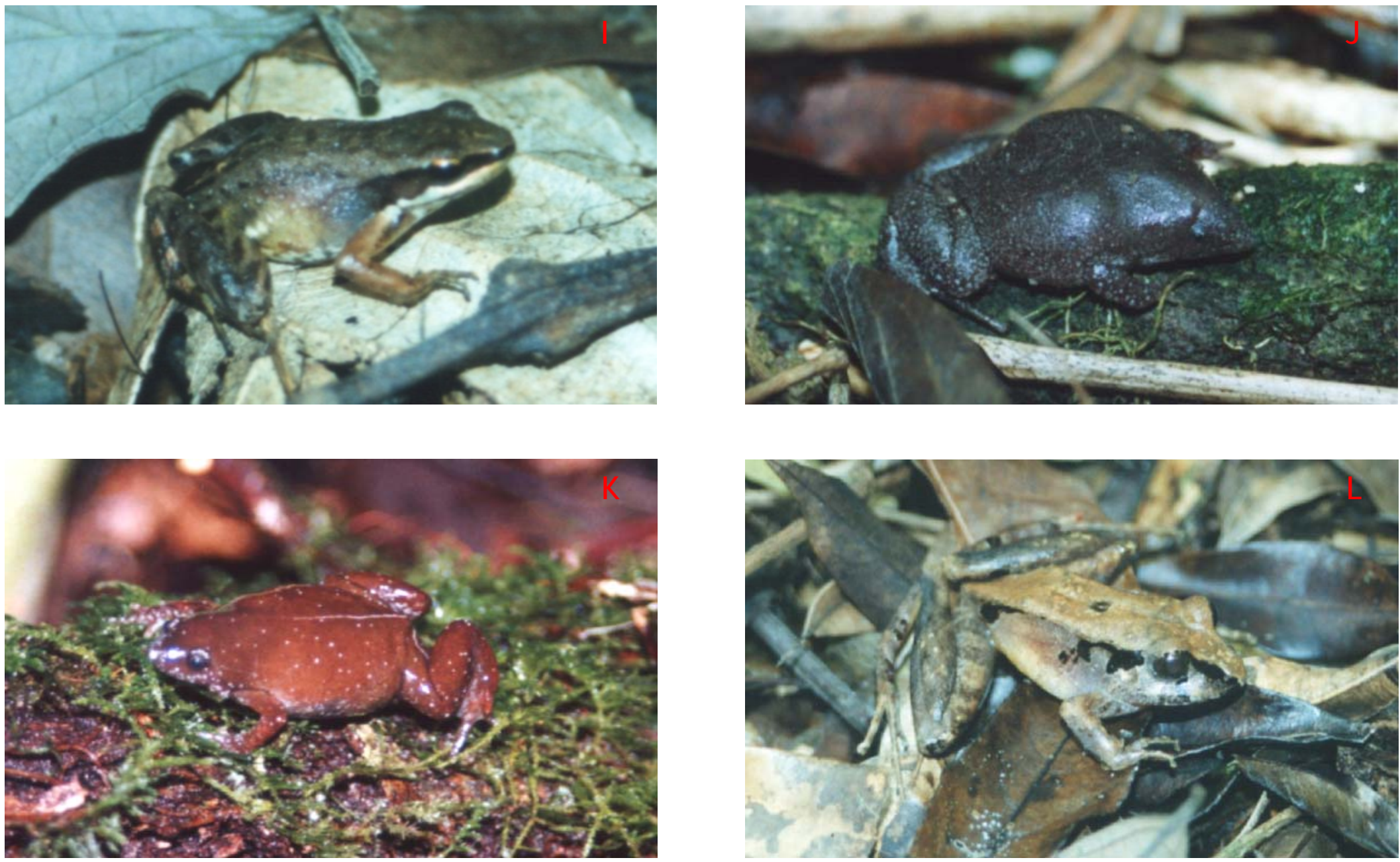

Figura 4 - I - Crossodactylus caramaschii; J - Myersiella microps; K - Chiasmocleis leucosticta; L Eleutherodactylus guentheri 


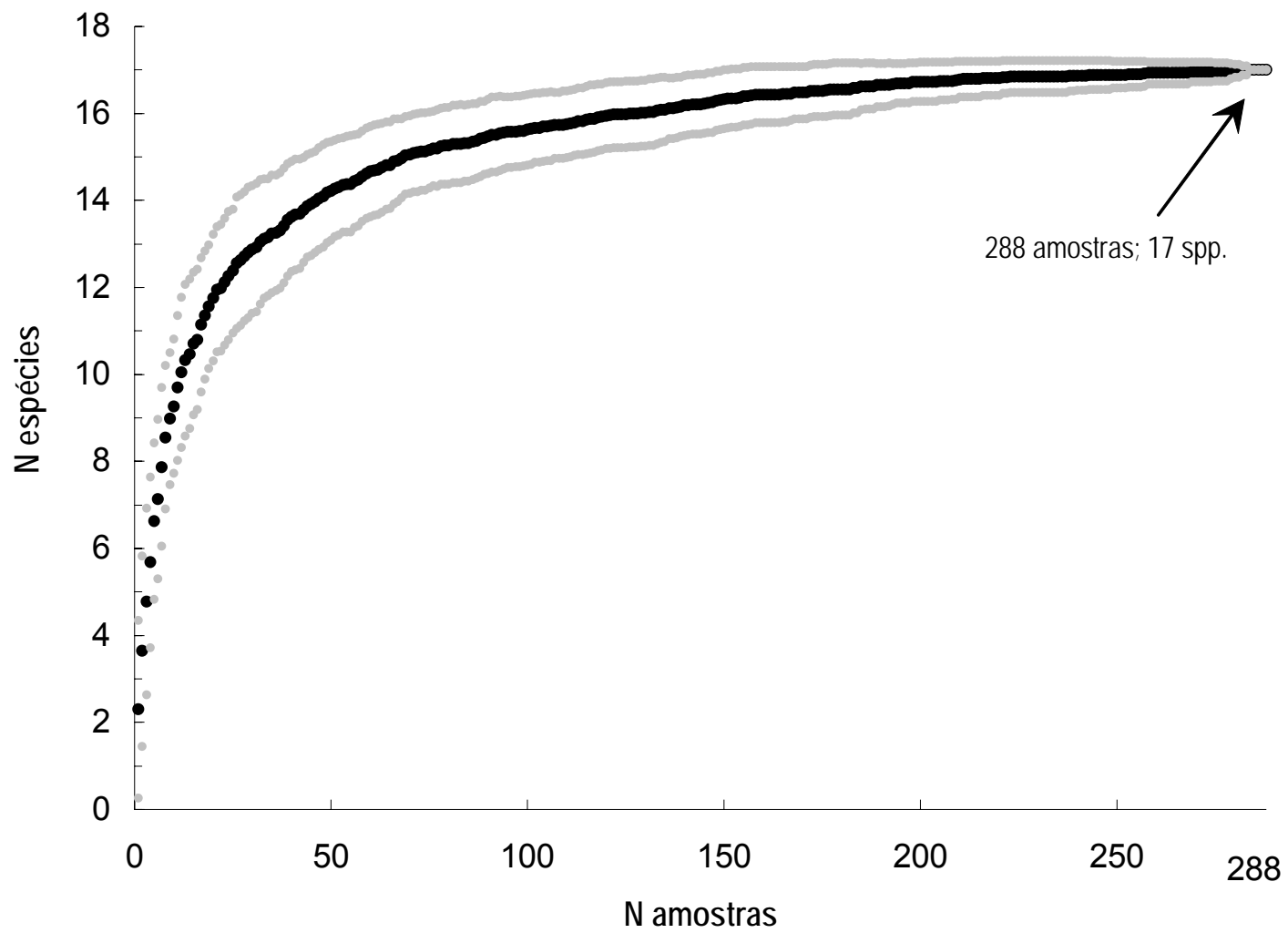

Figura 5 - Curva de rarefação de espécies para as 288 amostras nos ambientes estudados: floresta contínua, fragmentos circundados por plantios de E. saligna e plantios de E. saligna 


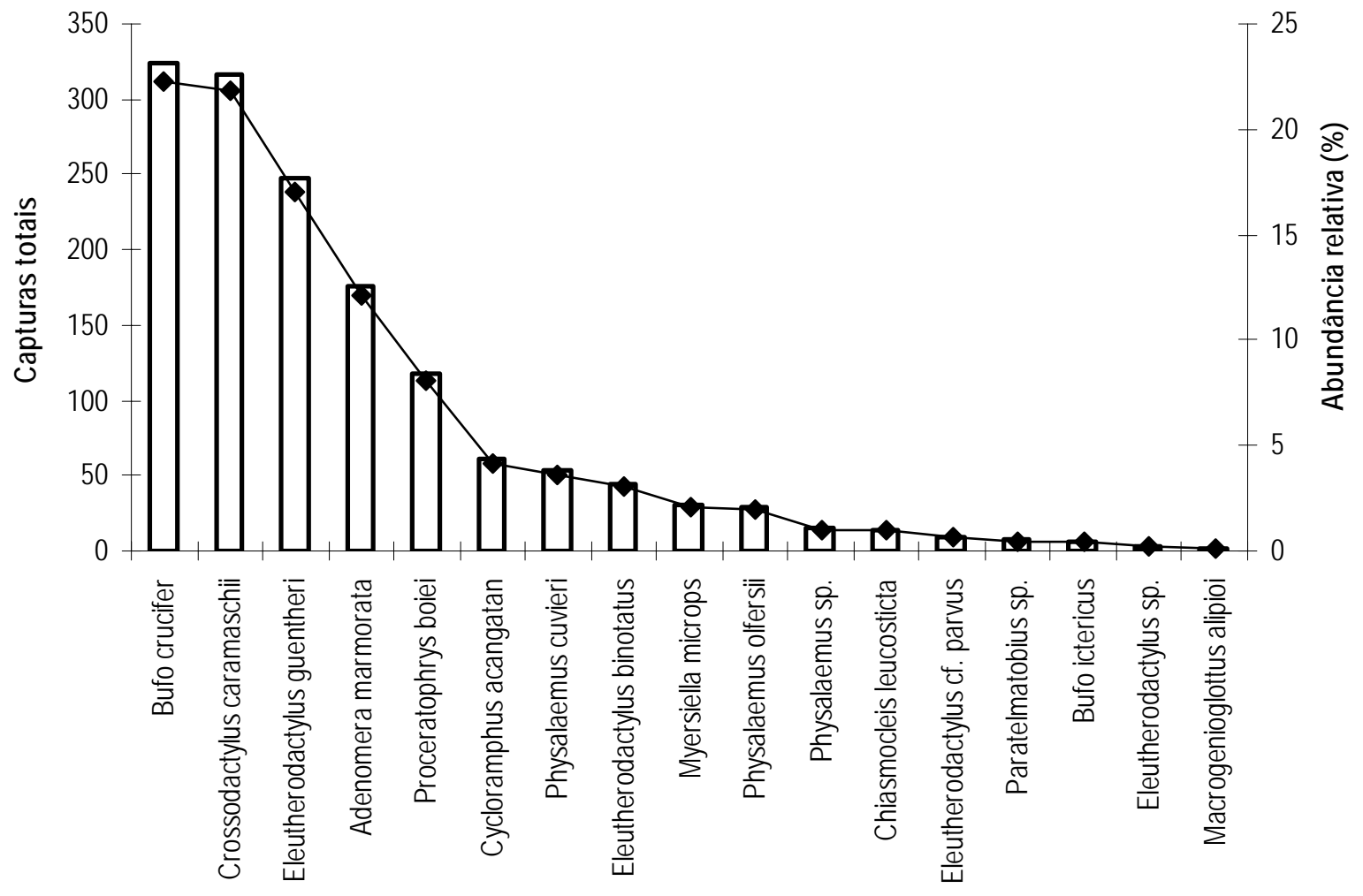

Figura 6 - Capturas totais e abundancia relativa (\%) das diferentes espécies de anuros verificadas na Fazenda João XXIII entre fevereiro de 2000 e janeiro de 2001

3.3 Riqueza, diversidade e abundância relativa das espécies de anuros de serapilheira em floresta contínua, fragmentos circundados por plantios de E. Saligna e plantios de E. Saligna

A floresta contínua foi o único ambiente em que todas as espécies foram registradas; duas espécies ocorreram exclusivamente neste ambiente: Macrogenioglottus alipioi e Eleutherodactylus sp. Nos plantios de E. saligna também não foram verificadas as espécies Eleutherodactylus cf. parvus e Paratelmatobius sp. A curva de rarefação de espécies apresentou um crescimento relativamente rápido, em todos os ambientes, até 
aproximadamente 20 amostras. A partir deste ponto até o final das 72 amostras, observou-se nos plantios de $E$. saligna um acréscimo de espécies lento e constante, é a curva que aparentemente está mais distante da estabilização. A curva de rarefação de espécies para os fragmentos circundados por $E$. saligna apresentou um crescimento relativamente lento e constante, especialmente a partir de 20 amostras até próximo a 100 amostras, e provavelmente foi o único ambiente em que a curva estabilizou, sendo possível que todas as espécies de anuros de serapilheira tenham sido registradas. Na floresta também se nota um crescimento lento e constante e o desvio apresentado no final das 108 amostras indica que possivelmente a curva está próxima à estabilização. (Figura 7).

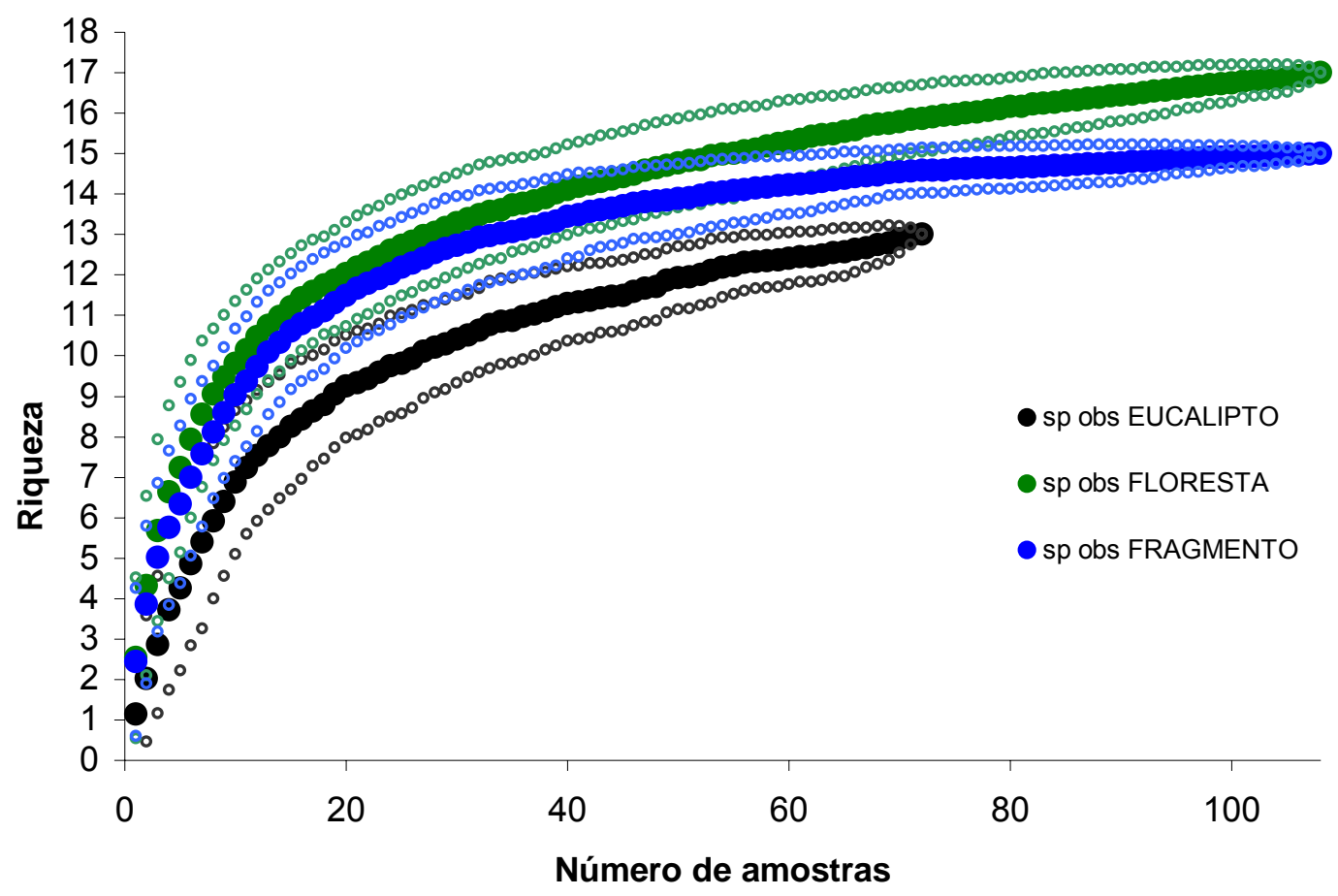

Figura 7 - Curva de rarefação de espécies para as 72 amostras em plantios de E. saligna, 108 amostras em floresta contínua e 108 amostras em fragmentos circundados por plantios de E. saligna 
Um resumo da diversidade e da riqueza estimada das espécies em cada ambiente e total é apresentado na Tabela 3. O teste de Kruskal-Wallis $(H)$ mostrou resultados significativos $(p<0,001)$ em todas as variáveis dependentes consideradas para os ambientes estudados - abundância $(H=19,1328, p<$ $0,0001)$, riqueza $(H=25,9582 ; p<0,0001)$, dominância $(H=24,1888 ; p<$ $0,0001)$, diversidade $(H=24,0379 ; p<0,0001)$ e eqüitabilidade $(H=16,0386 ; p$ $<$ 0,0003). $O$ teste de Dunn mostrou diferença significativa $(p<0,001)$ dessas variáveis nos ambientes de floresta - floresta contínua e fragmentos circundados por plantios de $E$. saligna - com os plantios de $E$. saligna, com exceção da eqüitabilidade entre a floresta contínua e plantios de E. saligna que foi significativa com $p<0,005$.

A espécie dominante na floresta contínua foi Crossodactylus caramaschii, representada por $25,27 \%$ do total de indivíduos capturados, quando somada as capturas de Eleutherodactylus guentheri, Bufo crucifer essas três espécies correspondem a $64,71 \%$ do total de indivíduos deste ambiente. Um grupo intermediário de seis espécies (A. marmorata, Cycloramphus acangatan, P. boiei, M. microps, P. olfersii e E. binotatus), com abundâncias relativa entre 2 e $10 \%$, acumulam $31,74 \%$ dos indivíduos. Os $3,54 \%$ restante da comunidade estudada referem-se a oito espécies com abundâncias menores que 1 \% (Figura 8).

Nos fragmentos circundados por plantios de $E$. saligna a espécie dominante também foi $C$. caramaschii representando $26,33 \%$ da comunidade, seguida por E. guentheri com $21,39 \%$ do total de indivíduos. A. marmorata, $P$. boiei e $B$. crucifer reúnem $38,21 \%$ dos indivíduos apurados nesse ambiente. Nas 10 espécies mais raras, cinco delas com abundância relativa menor que 1 $\%$, constata-se $14,63 \%$ da abundância absoluta.

Nos plantios de E. saligna, B. crucifer foi responsável por $60,85 \%$ dos indivíduos averiguados. $P$. cuvieri, a segunda espécie em abundância $(14,34 \%)$, unida as quatro espécies seguintes em abundância ( $A$. marmorata, E. binotatus, Physalaemus sp. e C. caramaschii) representam $31,78 \%$ dos 
indivíduos e as outras sete espécies registradas nos plantios representam 6,20 $\%$ da comunidade de anuros de serapilheira nesse ambiente.

Os pontos de borda e os de interior dos ambientes estudados não mostraram diferença significativas com a abundância $(H=0,2662$; $p<0,8754)$, dominância $(H=2,5819 ; p<0,2750)$, diversidade $(H=2,0874$; $p<0,3521)$, eqüitabilidade $(H=3,8603 ; p<0,1451)$ e riqueza $(H=0,2373$; $\mathrm{p}<0,8881)$.

Tabela 3. Abundância absoluta, riqueza, estimador de riqueza Jackknife (Ŝ) dominância (de Simpson), eqüitabilidade e diversidade (de ShannonWiener) dos anuros coletados nos três ambientes amostrados entre fevereiro de 2000 e janeiro de 2001, na Fazenda João XXIII, Pilar do Sul, SP. FC $=$ Floresta contínua, $\mathrm{FR}=$ Fragmentos circundados por plantios de $E$. saligna e $\mathrm{EC}=$ Plantios de E. saligna

\begin{tabular}{ccccc}
\hline & \multicolumn{4}{c}{ Ambientes } \\
\cline { 2 - 5 } & FC & FR & EC & Total \\
\hline Número de indivíduos & 649 & 550 & 255 & 1454 \\
Riqueza total obtida & 17 & 15 & 13 & 17 \\
Riqueza estimada (Ŝ) & $19 \pm 1,15$ & $16 \pm 1$ & $15 \pm 1,33$ & $18,3 \pm 1,33$ \\
Dominância (D) & 0,837 & 0,83 & 0,6 & 0,848 \\
Diversidade (H') & 2,066 & 2,012 & 1,437 & 2,127 \\
Eqüitabilidade & 0,729 & 0,743 & 0,56 & 0,751 \\
\hline
\end{tabular}

Nas Tabelas 4, 5 e 6 são apresentados os dados das espécies recapturadas durante o trabalho de campo. Foram retirados os indivíduos que foram coletados ou morreram acidentalmente nas armadilhas devido às chuvas ou baixas temperatura. Em todos os ambientes os índices de recaptura foram baixos. Nos plantios de $E$. saligna foram três espécies com uma recaptura cada, e o maior índice foi para Eleutherodactylus binotatus com 1,11 vezes. Nos fragmentos circundados por plantios de E. saligna foram 34 recapturas 
distribuídas em cinco espécies e o maior valor do índice foi para Crossodactylus caramaschii com 1,23 vezes capturadas neste ambiente. Na floresta contínua tivemos 16 recapturas com maior valor do índice para Physalaemus olfersii com 1,20 vezes.

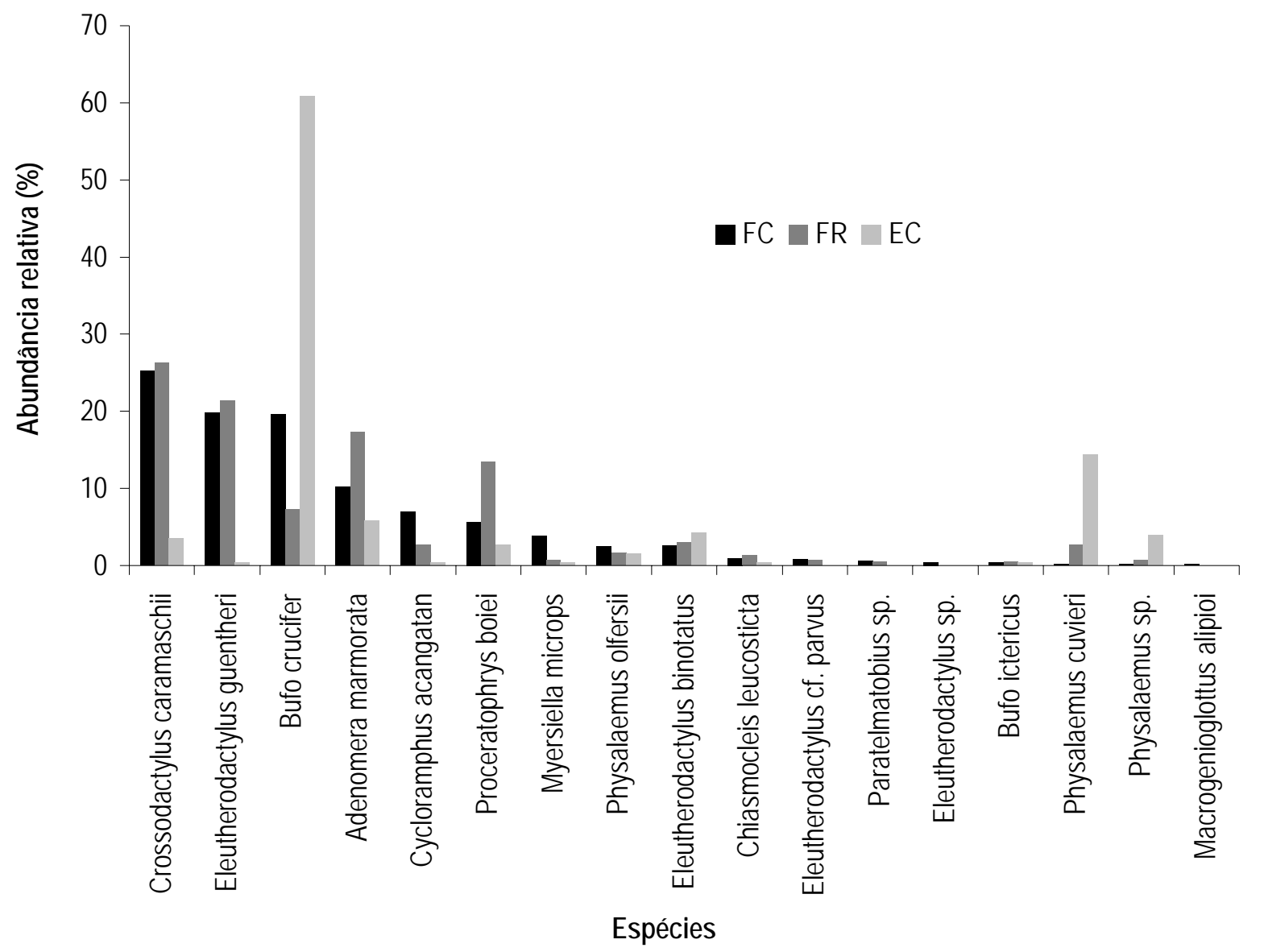

Figura 8 - Distribuição das abundâncias relativas de anuros coletados nos três ambientes amostrados entre fevereiro de 2000 e janeiro de 2001. $\mathrm{FC}=$ Floresta contínua, $\mathrm{FR}=$ Fragmentos circundados por plantios de $E$. saligna e EC = Plantios de E. saligna 
Tabela 4. Capturas totais, primeiras capturas e índice de recaptura em plantios de E. saligna, na Fazenda João XXIII, Município de Pilar do Sul

\begin{tabular}{lccc}
\hline \multirow{2}{*}{ Espécies } & \multicolumn{3}{c}{ Plantios de E. saligna } \\
\cline { 2 - 4 } & $\begin{array}{c}\text { Capturas } \\
\text { totais }\end{array}$ & $\begin{array}{c}\text { Primeiras } \\
\text { capturas }\end{array}$ & $\begin{array}{c}\text { Índice de } \\
\text { Recaptura }\end{array}$ \\
\hline Bufo crucifer & 135 & 134 & 1,01 \\
Eleutherodactylus binotatus & 10 & 9 & 1,11 \\
Physalaemus cuvieri & 35 & 34 & 1,03 \\
\hline
\end{tabular}

Tabela 5. Capturas totais, primeiras capturas e índice de recaptura em fragmentos circundados por plantios de E. saligna, na Fazenda João XXIII, Município de Pilar do Sul

\begin{tabular}{lccc}
\hline \multirow{2}{*}{ Espécies } & \multicolumn{3}{c}{ Fragmentos circundados por plantios de E. saligna } \\
\cline { 2 - 4 } & $\begin{array}{c}\text { Capturas } \\
\text { totais }\end{array}$ & $\begin{array}{c}\text { Primeiras } \\
\text { capturas }\end{array}$ & $\begin{array}{c}\text { Índice de } \\
\text { Recaptura }\end{array}$ \\
\hline Adenomera marmorata & 68 & 66 & 1,03 \\
Crossodactylus caramaschii & 116 & 94 & 1,23 \\
Eleutherodactylus guentheri & 91 & 84 & 1,08 \\
Physalaemus cuvieri & 15 & 13 & 1,15 \\
Proceratophrys boiei & 62 & 61 & 1,02 \\
\hline
\end{tabular}


Tabela 6. Capturas totais, primeiras capturas e índice de recaptura em floresta contínua, na Fazenda João XXIII, Município de Pilar do Sul

\begin{tabular}{lccc}
\hline \multirow{2}{*}{ Espécies } & \multicolumn{3}{c}{ Floresta contínua } \\
\cline { 2 - 4 } & $\begin{array}{c}\text { Capturas } \\
\text { totais }\end{array}$ & $\begin{array}{c}\text { Primeiras } \\
\text { capturas }\end{array}$ & $\begin{array}{c}\text { Índice de } \\
\text { Recaptura }\end{array}$ \\
\hline Adenomera marmorata & 46 & 45 & 1,02 \\
Bufo crucifer & 108 & 107 & 1,01 \\
Crossodactylus caramaschii & 116 & 106 & 1,09 \\
Eleutherodactylus guentheri & 90 & 89 & 1,01 \\
Physalaemus olfersii & 12 & 10 & 1,20 \\
Proceratophrys boiei & 33 & 32 & 1,03 \\
\hline
\end{tabular}

\subsection{Relação entre a diversidade da anurofauna de serapilheira e as variáveis ambientais}

Verificou-se a relação de 11 variáveis ambientais com a distribuição das 17 espécies de anuros de serapilheira presentes nos pontos de coletas. Cinco variáveis - altura da serapilheira, cobertura do dossel (\%), número de morfoespécies do dossel $(C A P>15 \mathrm{~cm})$, média de altura do sub-bosque e número de indivíduos do dossel - foram significativamente correlacionadas com a abundância das espécies, sendo utilizadas para a ordenação dos pontos amostrados e das espécies na Análise de Correspondência Canônica (ACC). A Figura 11 ilustra a ordenação dos pontos amostrais e das espécies ao longo do $1^{\circ}$ e $2^{\circ}$ eixos da ACC e os vetores ambientais sobre os quais a análise foi gerada. A variância total explicada por estas cinco variáveis foi de $52 \%$.

A floresta contínua e os fragmentos circundados por plantios de $E$. saligna apresentaram características ambientais muito próximas. Esses ambientes se caracterizam por uma grande densidade de árvores jovens, com sub-bosque bastante desenvolvido. Os plantios de E.saligna apresentaram uma 
maior entrada de luz, devido a menor densidade de árvores no estrato arbóreo e domínio de uma única espécie ( $E$. saligna) e serapilheira mais espessa. Com a análise de correspondência é possível verificar uma associação entre espécies e ambientes. Observa-se que existe uma clara separação entre os ambientes estudados. Os plantios de $E$. saligna encontram-se do lado negativo do eixo 2 e a maioria dos ambientes de floresta nativa (floresta contínua, FC e fragmentos circundados por plantios de E.saligna, EC) concentra-se no lado positivo deste eixo.

O eixo 1 da ACC (autovalor: 0,42; $p<0,01$ ) está positivamente ligado às variáveis ambientais cobertura do dossel, número de morfoespécies do dossel, número de indivíduos do dossel e média de altura no sub-bosque. Essas variáveis apresentam maiores valores nos ambientes de floresta nativa (floresta contíunua, FC e fragmentos circundados por plantios de E. saligna, FR) onde também aparece um maior número de espécies, concordando com as outras análises onde esses ambientes apresentaram maior diversidade. As espécies associadas aos ambientes florestais foram: Cycloramphus acangatan, C. caramaschii, P. boiei, M. microps, E. cf. parvus, C. leucosticta, E. guentheri, A. marmorata, Paratelmatobius sp. e $P$. olfersii; demonstrando uma preferência dessas espécies por características que demonstram uma maior complexidade no ambiente, como a maior riqueza e abundância de espécies no dossel. Negativamente a este eixo temos a altura da serapilheira, que apresentou maiores valores nos plantios de E. saligna. Associada aos plantios de E. saligna encontram-se as espécies: $P$. cuvieri, Physalaemus sp. e B. crucifer. $\mathrm{O}$ eixo 2 (autovalor: 0,$19 ; p<0,01$ ) é formado pelas contribuições positivas $P$. olfersii e $E$. binotatus; e negativa das espécies $B$. ictericus e A.marmorata, espécies com maior abundância nos ambientes de floresta nativa (Figura 9). 
Axis 2

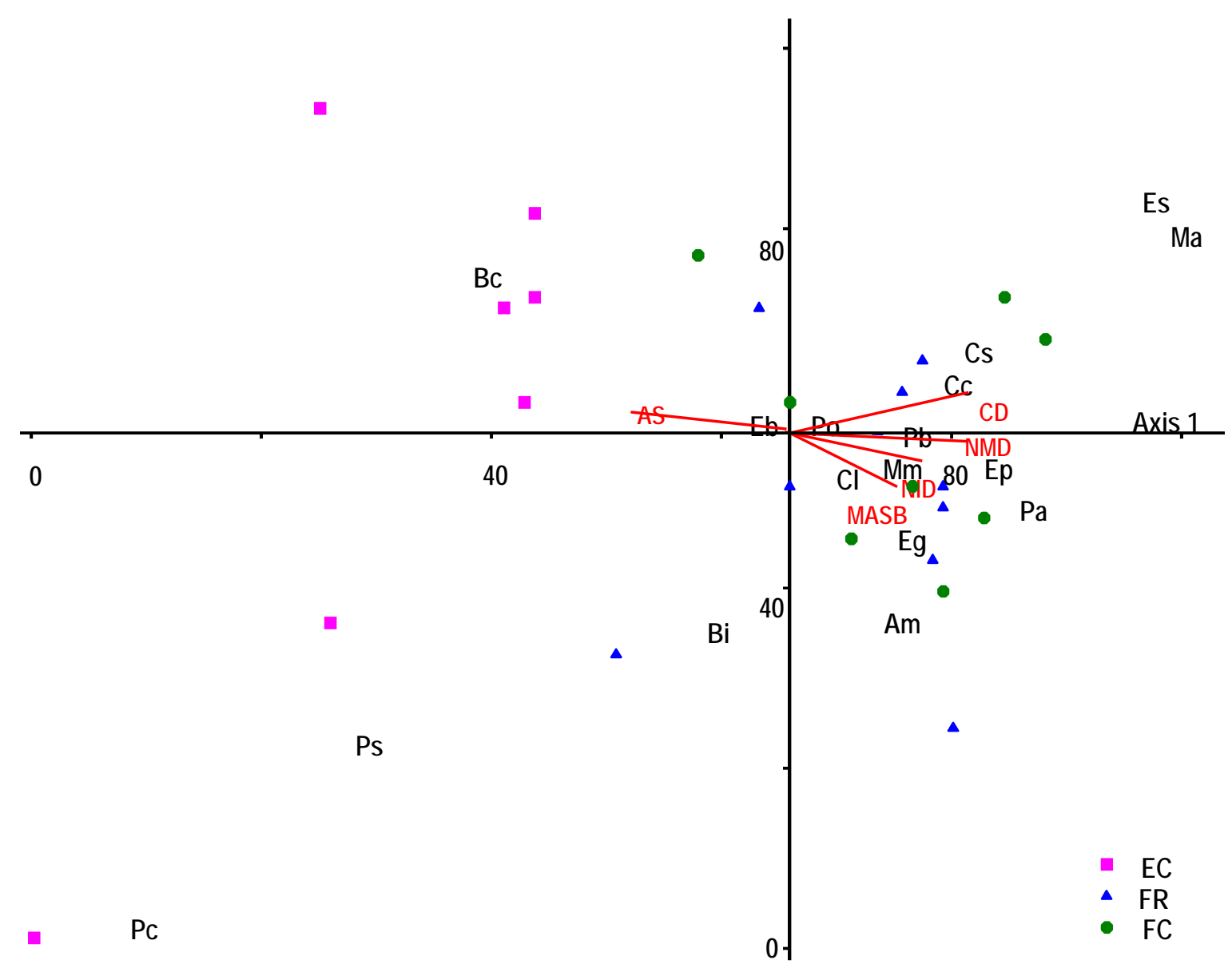

Figura 9 - Diagrama de ordenação ("triplot" ou Axis 3) dos diferentes tratamentos e das espécies ao longo dos $1^{\circ}$ e $2^{\circ}$ eixos da Análise de Correspondência Canônica (ACC), geradas a partir de cinco varáveis ambientais. Vetores das variáveis ambientais: $\mathrm{AS}=$ altura da serapilheira, $\mathrm{CD}=$ cobertura do dossel, $\mathrm{NMD}=$ número de morfoespécie do dossel, NID = número de indivíduos do dossel e MASB = média de altura do sub-bosque. Tratamentos: $F C=$ floresta contínua, $\mathrm{FR}=$ fragmentos circundados por plantios de $E$. saligna, $\mathrm{EC}=$ plantios de $E$. saligna. Espécies: $\mathrm{Am}=A$. marmorata, $\mathrm{Bc}=B$. crucifer, $\mathrm{Bi}=B$. ictericus, $\mathrm{Cc}=$ C. caramaschii, $\mathrm{Cl}=\mathrm{C}$. leucosticta, $\mathrm{Cs}=$ Cycloramphus acangatan, $\mathrm{Eb}=E$. binotatus, $\mathrm{Ep}=\mathrm{E}$. cf. parvus, $\mathrm{Eg}=\mathrm{E}$. guentheri, $\mathrm{Es}=$ Eleutherodactylus sp., $\mathrm{Ma}$ 
$=$ M. alipioi, $\mathrm{Mm}=$ M. microps, $\mathrm{Pb}=\mathrm{P}$. boiei, $\mathrm{Pc}=P$. cuvieri, $\mathrm{Po}=P$. olfersii, $\mathrm{Pa}$ = Paratelmatobius sp. e Ps = Physalaemus sp.

\subsection{A influência do período na captura de anuros de serapilheira}

A análise de Kruskal-Wallis mostrou diferença significativa entre as estações e a abundância $(H=93,8950 ; p<0,0001)$, dominância $(H=59,1826$; $p<0,0001)$, diversidade $(H=66,9731 ; p<0,001)$, eqüitabilidade $(H=34,1130$; $p<0,0001)$ e riqueza $(H=84,2036 ; p<0,0001)$. Com o teste de Dunn foi possível separar o período de coleta em duas estações, este teste não apresentou diferença significativa $(p<0,001)$ entre o verão e primavera, denominados então como verão, e entre o outono e o inverno, denominados como inverno. O verão foi responsável por $80,74 \%$ do total de indivíduos capturados, destes 45,32 \% ocorreram na floresta contínua (Figura 10D); a única espécie não registrada nesse período foi Eleutherodactylus sp..

$\mathrm{Na}$ floresta contínua, $C$. caramaschii e $B$. crucifer foram as espécies mais abundantes no verão com $23,31 \%$ e $22,56 \%$ do total de indivíduos coletados, respectivamente. As espécies $P$. boiei, E. cf. parvus, B. ictericus, M. alipioi e $P$. cuvieri foram registradas somente nesse período (Figura 10A). B. ictericus, $M$. alipioi e $P$. cuvieri ocorreram somente nos meses de verão com pluviosidade maior que $100 \mathrm{~mm}$. Durante o inverno as espécies mais abundantes foram $C$. caramaschii e E. guentheri, representando juntas $67,52 \%$ do total de capturas nesse período. Eleutherodactylus sp. e Physalaemus sp. foram registradas somente no inverno.

Nos fragmentos circundados por plantios de E. saligna (Figura 10B), C. caramaschii e A. marmorata foram as espécies mais abundantes no verão, com $23,56 \%$ e $22,36 \%$ dos anuros de serapilheira registrados nesse período. $M$. microps, $P$. cuvieri e $P$. boiei ocorreram nesse ambiente apenas durante $o$ verão; M. microps foi capturada somente nos meses mais chuvosos do verão. No inverno, E. guentheri e C. caramaschii representaram $70,90 \%$ do total de 
indivíduos coletados; E. cf. parvus, Paratelmatobius sp. e Physalaemus sp. ocorreram nesse ambiente somente no inverno.

Nos plantios de E. saligna, B. crucifer foi dominante nas duas estações, com abundância relativa de 64,60 \% durante o verão e 37,93 \% no inverno (Figura 10C). Das 13 espécies capturadas nesse ambiente todas as espécies ocorreram no verão e apenas quatro foram observadas durante o inverno: $B$. crucifer, Physalaemus sp., C. caramaschii, E. binotatus. 

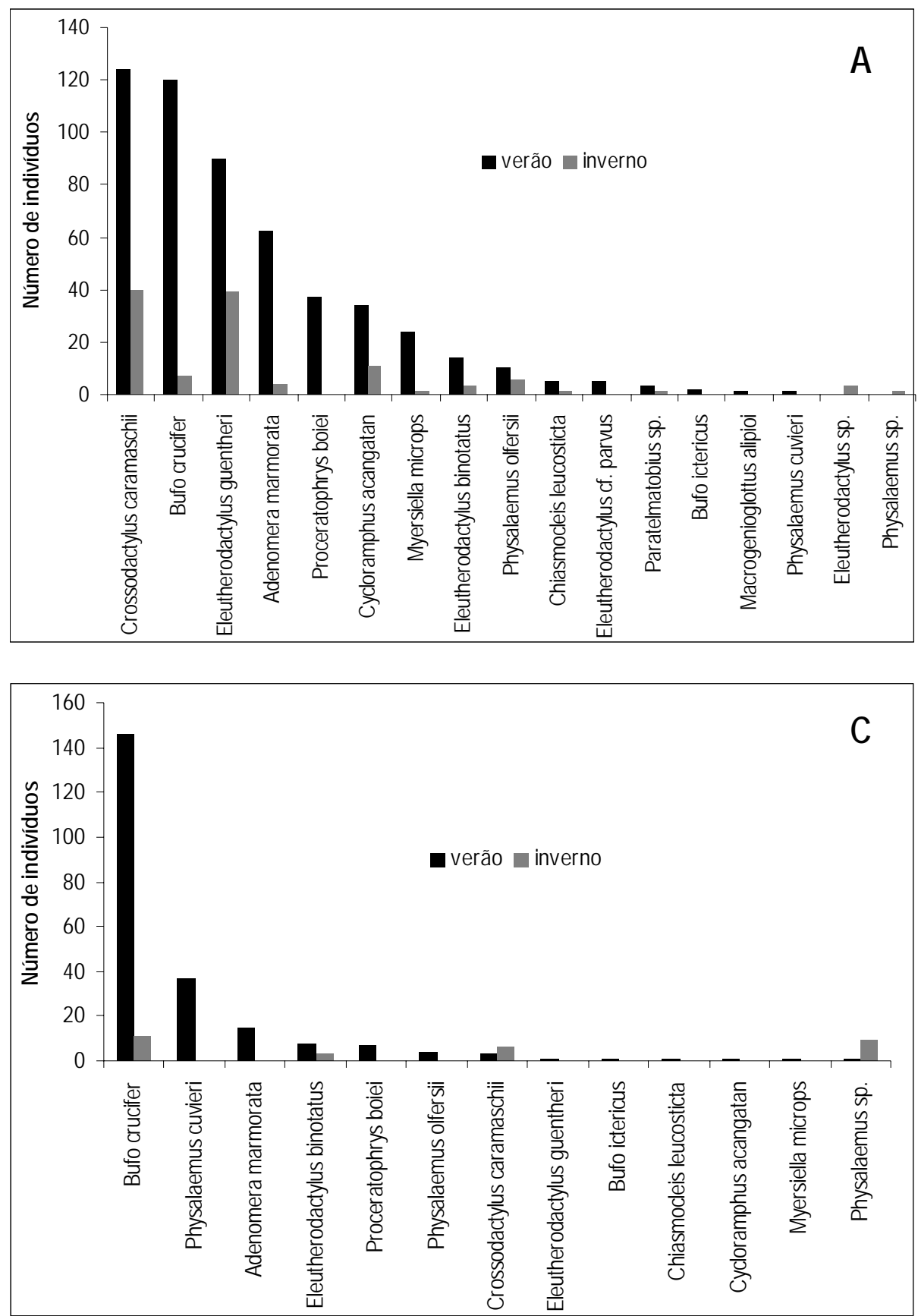
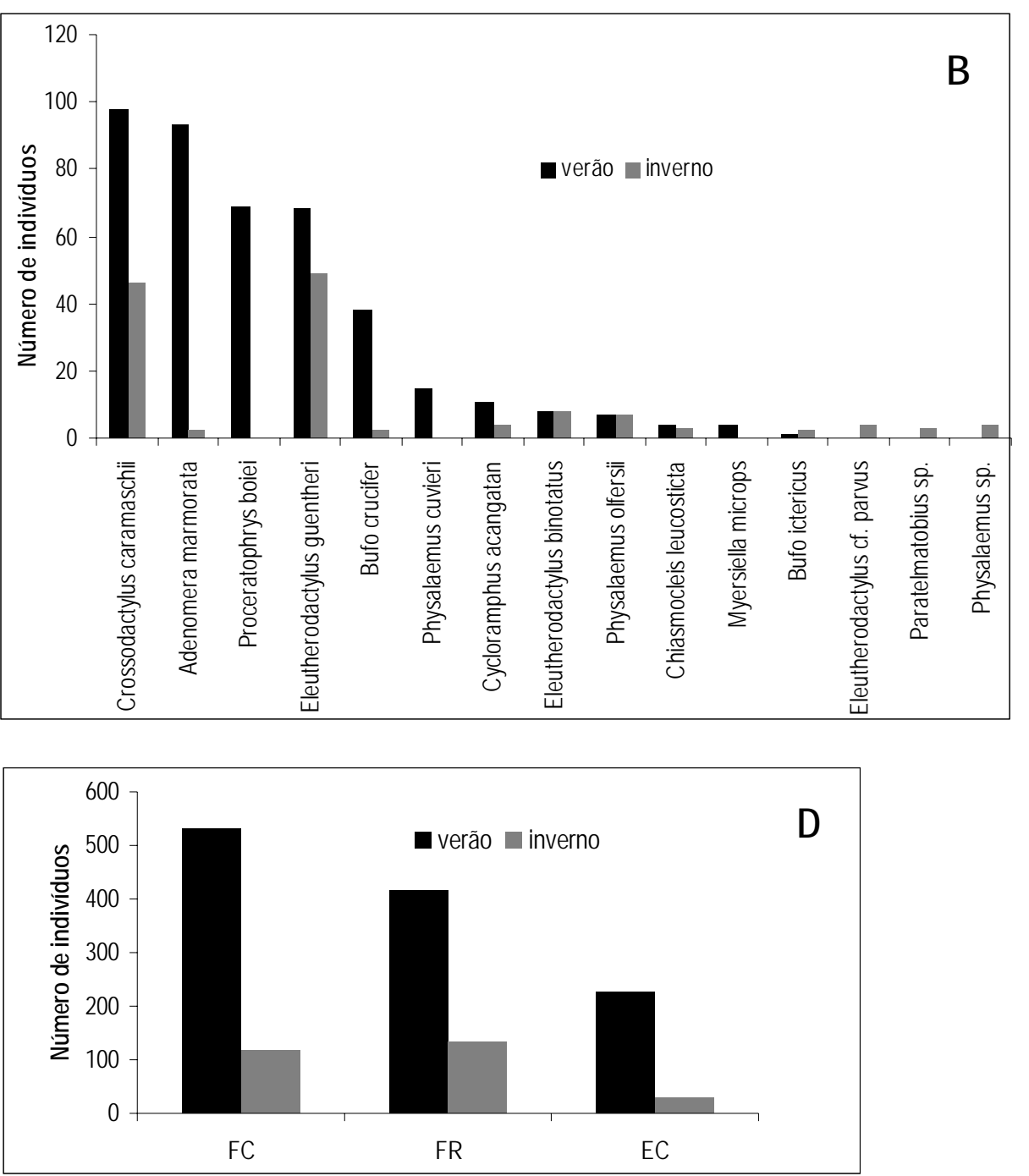

Figura 10 - Número de indivíduos das diferentes espécies observadas durante o verão e o inverno na floresta contínua, $F C(A)$; nos fragmentos circundados por plantios de E.saligna, FR (B) e plantios de $E$. saligna, EC (C). Número total de captura em cada ambiente (D). 


\section{DISCUSSÃO}

\subsection{A comunidade de anfíbios anuros da Fazenda João XXIII}

Um grande número de anfíbios anuros verificados na Fazenda João XXIII coincide com espécies registradas em outras localidades de Floresta Atlântica inventariadas, como em Boracéia (Heyer et al., 1990), Serra do Japi (Haddad \& Sazima, 1992), Fazendinha São Luís (Pombal-Jr, 1995), Ilha de São Sebastião (Sawaya, 1999) e no Parque Estadual de Intervales (Bertoluci \& Rodrigues, 2002). A riqueza encontrada no local de estudo é inferior a algumas das localidades citadas. As espécies foram levantadas no decorrer da coleta com armadilhas de interceptação e queda e através do trabalho realizado por Antunes (2003), em incursões aleatórias na área de estudo, por meio de procura visual e auditiva em ambientes propícios. Portanto, não devendo ser considerada completa. Como este estudo teve enfoque nos anuros de serapilheira, a utilização de outros métodos deve aumentar consideravelmente a lista de espécies.

Nos ambientes de floresta nativa, as espécies dominantes foram Crossodactylus caramaschii e Eleutherodactylus guentheri, espécies que estão associadas a ambientes florestados. Nos plantios de $E$. saligna as duas espécies mais abundantes, Bufo crucifer e Physalaemus cuvieri, são normalmente encontradas em áreas abertas, ocorrendo em uma grande variedade de hábitats. Adenomera marmorata apresentou uma abundância maior nos fragmentos circundados por plantios de $E$. saligna; esta espécie é comum em ambientes florestados do sudeste do Brasil, mesmo em florestas 
secundárias e capoeiras. B. crucifer e A. marmorata são espécies oportunistas e normalmente invadem áreas degradadas. Macrogenioglottus alipioi é um exemplo de espécie rara com ampla distribuição ao longo da Floresta Atlântica, ocorrendo do sul da Bahia até São Paulo, mas sempre de forma pontual. Segundo Haddad $^{2}$ Chiasmocleis leucosticta é uma espécie com reprodução explosiva normalmente após fortes chuvas; a não coincidência do período de coleta com o reprodutivo pode ser responsável por esta espécie estar entre aquelas com menores abundâncias.

Aplastodiscus perviridis ocorre em regiões montanhosas do sul e sudeste do Brasil, habitando áreas abertas com vegetação arbustiva, mas não florestas fechadas (Kewt, 1999). Neste estudo dois espécimes foram capturados, um nos plantios de $E$. saligna e outro no fragmento próximo a uma clareira.

Em estudo conduzido no Parque Estadual de Intervales Bufo crucifer, Physalaemus olfersii, Hyla faber, H. prasina, H. bischoffi, H. minuta e H. microps foram consideradas generalistas quanto à utilização de sítios reprodutivos, usando corpos d'água nos três tipos de ambientes estudados: florestas, borda de mata e áreas abertas; Scinax fuscovarius foi considerada especialista de área aberta (Bertoluci \& Rodrigues, 2002). H. faber, H. prasina, H. bischoffi, $H$. minuta e $H$. microps são espécies que ocorrem no sul e sudeste do Brasil e estão associadas a ambientes florestais, podendo ser encontradas em áreas abertas durante o período de acasalamento (Kewt, 1999). Na Fazenda João XXIII esses hilídeos, assim como $H$. albopunctata, foram registradas em corpos d'água permanentes sobre vegetação baixa, com machos vocalizando nos meses de fevereiro a abril. S. fuscovarius vive em áreas abertas e na época reprodutiva pode ser encontrada em corpos d'água parada; na área também foi encontrada em ambiente aberto.

A presença na área de estudo do híbrido de Phyllomedusa extende a sua distribuição, antes conhecida, no Estado de São Paulo, apenas para o município de Ribeirão Branco, reforçando a sugestão de Haddad et al.(1994) de 
que deve haver uma extensa zona no interior do Estado em que Phyllomedusa tetraploidea ocorre em simpatria com Phyllomedusa distincta.

Segundo Cruz \& Peixoto(1948), as espécies do grupo Hyla albosignata são restritas à Floresta Atlântica. $\mathrm{Na}$ área de estudo $H$. albosignata foi registrada na floresta contínua.

\subsection{Anuros de serapilheira na Fazenda João XXIII}

Na Fazenda João XXIII com o esforço amostral de 1728 armadilhas-dias, tivemos um sucesso de captura de $84,44 \%$. Dixo (2001), utilizando armadilhas de interceptação e queda na Reserva Biológica de Una, encontrou 18 espécies de anuros com um esforço amostral de 2592 armadilhas-dia, um sucesso de captura de 94,44 \%. A mesma autora, utilizando baldes de 35 litros, não considerou em sua análise de dados um espécime de Eleutherodactylus cf. guentheri e cinco espécimes de Eleutherodactylus binotatus, justificando que essas espécies são capazes de fugir das armadilhas, saltando fora dos baldes e escalando cercas-guias, sendo portanto sub-amostradas pelo método utilizado. Durante o presente trabalho, foram utilizados baldes maiores (ver Material e Métodos), sendo capturados 247 indivíduos de Eleutherodactylus guentheri e 44 indivíduos de Eleutherodactylus binotatus, justificando sua inclusão nas análises realizadas.

São poucos os trabalhos quantitativos realizados enfocando a diversidade de anuros em Floresta Atlântica no Estado de São Paulo e a utilização de métodos diferentes dificulta a comparação entre diferentes estudos. Giaretta (1999) apresenta uma lista de 21 espécies de anuros de serapilheira para Ubatuba, entre 0 e 100 m de altitude, não utilizando estimador de riqueza. Sawaya (1999), em trabalho conduzido na llha de São Sebastião, com altitude entre 0 e $900 \mathrm{~m}$, registrou 15 espécies e obteve um número de 20 $\pm 3,16$ espécies estimadas para o local. No presente trabalho foram verificadas 
17 espécies de anuros de serapilheira e uma riqueza estimada em 18,3 $\pm 1,33$ espécies, em transeções onde a altitude variava de 750 a 980 m. Allmon (1991) propõe um número de aproximadamente 20 espécies para florestas tropicais de baixa altitude, o que parece se aplicar às localidades estudadas de Floresta Atlântica como Ubatuba e Illha de São Sebastião, bem como ao trabalho em Pilar do Sul.

Scott (1976) sugere uma diminuição no número de espécies com o aumento da altitude e do número de meses com pluviosidade menor que 100 mm (meses secos). Giaretta (1997) encontrou 11 espécies na Serra do Japi em área amostrada entre 850 e 1000 m e com três a quatro meses secos. Sawaya (1999) relacionou o menor número de espécies na Serra da Mantiqueira que na Serra do Mar, com as maiores altitudes, menor pluviosidade e a ocorrência de um maior número de meses secos, ressaltando a dificuldade de comparação entre as duas serras, devido às menores reservas e maior grau de perturbação antrópica na Serra da Mantiqueira.

Conforme a Tabela 7, as áreas amostradas nesse trabalho contemplam uma amplitude altitudinal e pluviosidade semelhantes às da Serra da Mantiqueira, com ocorrência de um maior número de meses secos. Mesmo assim apresentou uma riqueza equivalente às observadas em áreas da Serra do Mar, o que provavelmente pode estar relacionado à proximidade de extensas áreas de remanescentes de Floresta Atlântica.

Normalmente é esperada uma alta eqüitabilidade na abundância relativa das espécies em florestas tropicais (Lloyd et al., 1968), o que caracterizaria uma baixa dominância. Como observado para a maioria das comunidades ou taxocenoses (Krebs, 1989), a Fazenda João XXIII apresentou poucas espécies dominantes e um maior número de espécies raras. Considerando os valores de dominância para algumas amostragens quantitativas em Floresta Atlântica, as apresentadas nesse trabalho possuem uma variação consideravelmente menor e a única espécie coincidente é $E$. guentheri, dominante também no inverno na 
Serra da Mantiqueira, apresentando nesta praticamente o dobro do valor de dominância.

A teoria da biogeografia de ilhas propõe um menor número de espécies em áreas menores e mais isoladas (MacArthur \& Wilson, 1967). Na fragmentação da floresta o grau de isolamento é um dos fatores que determina, em parte, a severidade das mudanças na composição da comunidade (Laurance, 1991a; Gascon et al., 1999) e mesmo o aumento da riqueza específica nos fragmentos, como observado na Amazônia Central por Tocher et al. (1997). Aumentando ou mantendo a conectividade da paisagem, pode-se reduzir a extinção de espécies e prevenir uma eventual depressão da reprodução em fragmentos isolados (Noss, 1987; Benett, 1990; Henein \& Merriam, 1990; Meffe \& Carrol, 1994; Laurance \& Gascon, 1997). Dixo (2001) não encontrou diferenças significativas na diversidade de anuros de serapilheira em hábitats naturais e ambientes florestais antrópicos, cabruca e capoeira, e atribui a manutenção da comunidade estudada a conectividade entre os fragmentos proporcionada pelos ambientes florestais antrópicos. Na Fazenda João XXIII, embora a riqueza específica nos fragmentos circundados por E. saligna tenha sido menor, a diversidade deste ambiente não apresentou diferenças significativas quando comparada com a floresta contínua; no entanto, esses dois ambientes foram significativamente diferentes quando comparados com os plantios de E. saligna. As cabrucas são plantações de cacau sob matas rarefeitas. Por outro lado, nos plantios de E. saligna toda a vegetação nativa é retirada para a implantação dos talhões e o corte acontece periodicamente (mais ou menos sete anos). Essa diferença na dinâmica das matrizes aparentemente pode estar influenciando nos resultados obtidos na Fazenda João XXIII, já que nesta matriz alterações geradas indiretamente pelas mudanças ambientais, como temperatura, luminosidade, exposição a ventos e mesmo umidade devem ser mais drásticas que nas cabrucas.

A riqueza de espécies também está fortemente correlacionada ao esforço de amostragem (Melo et al., 2003). Assim, quanto maior o número de 
indivíduos capturados espera-se uma maior riqueza de espécies. A diferença no tamanho da amostra pode ter influenciado no menor número de espécies observadas nos plantios de E. saligna.

Lima e Gascon (1999) verificaram que fragmentos de pequena largura (140-190 m) na Amazônia central apresentavam composição e abundância de anuros de serapilheira semelhantes àquelas da floresta contínua adjacente. Dixo (2001) encontrou resultados semelhantes e, assim como neste trabalho, não foram observados efeitos evidentes de borda sobre a diversidade de anuros de serapilheira.

Análises incorporando as varáveis ambientais mostram que a grande maioria das espécies prefere a floresta contínua e os fragmentos circundados por E. saligna. A ordenação das espécies mostra uma clara separação dos ambientes de floresta nativa e os plantios de E. saligna. B. crucifer é mais abundante em ambientes alterados. O número relativamente alto de variáveis ambientais relacionadas às abundâncias das espécies, provavelmente indica diferenças nas preferências de hábitat de cada uma delas.

Estudos sobre as conseqüências da fragmentação das florestas, ainda incipientes, estão permitindo conhecer como as espécies de plantas e animais respondem a diminuição e isolamento das áreas. No entanto, não existe uma resposta padronizada, pois cada histórico de perturbação é diferente e as espécies parecem comportar-se diferentemente a essas alterações. $O$ acúmulo de estudos como este auxiliará na compreensão dos processos envolvidos na fragmentação de florestas tropicais e seus efeitos sobre a fauna.

\subsection{Considerações finais}

Os resultados encontrados neste trabalho ressaltam a importância de remanescentes florestais em áreas particulares para a conservação da anurofauna. Na Fazenda João XXIII, caracterizada por um mosaico de florestas nativas e plantios de $E$. saligna, ambiente também florestal funcionando como 
matriz, parece haver uma queda na riqueza específica com a diminuição da área de floresta e a simplificação da estrutura da vegetação. Embora a diferença encontrada entre os ambientes de florestas nativas não seja significativa, os fragmentos menores apresentaram um menor número de espécies. Quando comparados os remanescentes de Floresta Atlântica com os plantios de E. saligna, ainda que ocorram no local várias das espécies observadas nos ambientes florestais, é notória a queda na riqueza e, sobretudo, na abundância das espécies.

Por outro lado, o fato da área estar envolvida por uma matriz florestal antrópica pode estar minimizando o efeito de borda nos fragmentos de Floresta Atlântica estudados e funcionando como uma matriz permeável que poderia ser utilizada como hábitat e ambiente de deslocamento por algumas espécies entre os fragmentos de floresta. Resultado semelhante foi encontrado com estudo de pequenos mamíferos (Silva, 2001) desenvolvido na mesma área de estudo, mostrando que é possível haver uma relação positiva entre matriz florestal e a manutenção da diversidade local. É importante ressaltar que os resultados obtidos neste estudo devem ser aplicados apenas localmente, visto as circunstâncias em que os plantios de E. saligna estão inseridos, formando um mosaico, e a proximidade da fazenda às extensas áreas de Floresta Atlântica, como o Parque Estadual de Carlos Botelho e a APA da Serra de Tapiraí.

As diferenças em abundância de espécies entre os diferentes ambientes amostrados na Fazenda João XXIII indica que algumas delas possuem restrições na ocupação dos plantios de E. saligna. A maioria das espécies está associada a ambientes florestais, muitas da região sul e sudeste do Brasil. Nos plantios de E. saligna a espécie dominante, Bufo crucifer, apresentou o maior valor de dominância. Normalmente esta espécie comporta-se como generalista ocorrendo em uma ampla variedade de hábitats. E. guentheri, uma das espécies mais abundante nos remanescentes de Floresta Atlântica, apresentou somente uma captura em plantio de E. saligna. 
Assim como em outros trabalhos quantitativos da anurofauna em Floresta Atlântica, a comunidade estudada na Fazenda João XXIII apresenta uma alta sazonalidade entre o inverno, período associado com temperaturas mais amenas e menor pluviosidade, e o verão associado as maiores temperaturas e volume de chuvas. E. guentheri, espécie normalmente associada a ambientes florestais, foi a espécie dominante durante o inverno, na floresta contínua e nos fragmentos circundados por $E$. saligna, coincidindo com resultados encontrados na Serra do Japi. Porém, neste local E. guentheri obteve um maior valor de dominância.

$\mathrm{Na}$ área em que o trabalho foi desenvolvido há várias espécies desconhecidas; no presente estudo foram verificadas quatro espécies novas, Paratelmatobius sp., Hylodes sp., Hyla sp. e Cycloramphus acangatan (Verdade \& Rodrigues, 2003), e três espécies indeterminadas Hyla sp., Eleutherodactylus sp., Physalaemus sp., aparentemente novas.

Alternativas de manejo nos plantios de E. saligna poderiam favorecer a anurofauna com o aumento da diversidade e não propiciar a ocupação deste ambiente por espécies generalistas como Bufo crucifer e Physalaemus cuvieri. Uma possibilidade seria a realização de cortes seletivos, onde só fosse retirada a cultura, mantendo-se o sub-bosque. Outra possibilidade seria a manutenção de talhões em idades diferentes, onde a anurofauna não seria exposta repentinamente a uma alteração brusca de extensas áreas abertas. A formação de corredores com espécies nativas unindo os fragmentos de Floresta Atlântica e a manutenção de uma borda de eucaliptos nos remanescentes, para que estes não sejam danificados a cada cortes, também poderiam melhorar as condições para a conservação desta fauna. 
Tabela 7. Resumo de resultados obtidos em trabalhos com anuros de serapilheira realizados em Floresta Atlântica do Estado de São Paulo

\begin{tabular}{|c|c|c|c|c|c|c|c|c|}
\hline Localidade & Estação & Riqueza & Espécie dominante & $\begin{array}{c}\text { Dominância } \\
(\%)\end{array}$ & $\begin{array}{c}\text { altitudes } \\
\text { amostradas } \\
(\mathrm{m})\end{array}$ & $\begin{array}{c}\text { Meses } \\
\text { secos/ano } \\
(<100 \mathrm{~mm})\end{array}$ & $\begin{array}{l}\text { Pluviosidade } \\
\text { /ano }(\mathrm{m})\end{array}$ & Fonte \\
\hline \multirow[t]{2}{*}{ Serra do Japi } & & 11 & & & $850-1000$ & 3 a 4 & 1,5 & $\begin{array}{c}\text { Giaretta et al. } \\
(1997)\end{array}$ \\
\hline & $\begin{array}{l}\text { verão } \\
\text { inverno }\end{array}$ & & $\begin{array}{c}\text { Eleutherodactylus } \\
\text { guentheri }\end{array}$ & 71,5 & & & & \\
\hline \multirow[t]{3}{*}{ Ubatuba } & & 21 & & & $0-1000$ & 1 a 2 & 2,5 & $\begin{array}{l}\text { Giaretta } \\
\text { (1999) }\end{array}$ \\
\hline & verão & & $\begin{array}{c}\text { Eleutherodactylus } \\
\text { parvus }\end{array}$ & 51,9 & & & & \\
\hline & inverno & & $\begin{array}{l}\text { Eleutherodactylus } \\
\text { parvus }\end{array}$ & 43,2 & & & & \\
\hline \multirow[t]{2}{*}{ Ilha de São Sebastião } & & 15 & & & $0-900$ & & & $\begin{array}{c}\text { Sawaya } \\
(1999)\end{array}$ \\
\hline & $\begin{array}{l}\text { verão } \\
\text { inverno }\end{array}$ & & $\begin{array}{l}\text { Eleutherodactylus } \\
\text { parvus }\end{array}$ & 34,0 & & & & \\
\hline \multirow[t]{3}{*}{ Pilar do Sul } & & 17 & & & $750-980$ & 6 & 1,4 & $\begin{array}{l}\text { presente } \\
\text { estudo }\end{array}$ \\
\hline & verão & & $\begin{array}{l}\text { Crossodactylus } \\
\text { caramaschii }^{1}\end{array}$ & 23,49 & & & & \\
\hline & inverno & & $\begin{array}{l}\text { Eleutherodactylus } \\
\text { guentheri }{ }^{1}\end{array}$ & 35,06 & & & & \\
\hline
\end{tabular}

${ }^{1}$ Essas espécies foram dominantes considerando apenas os ambientes de Floresta Atlântica, quando incluímos os plantios de E. saligna no verão $B$. crucifer é dominante $(25,94 \%)$ e no inverno C. caramaschii $(32,62 \%)$. 


\section{CONCLUSÕES}

1) A riqueza específica verificada na Fazenda João XXIII, aproximadamente 20 espécies de anuros de serapilheira, concorda com as observadas em florestas tropicais de baixa altitude em diferentes localidades.

2) A comunidade de anuros de serapilheira apresenta-se com um maior número de espécies raras. O padrão de riqueza e dominância apresentado nos ambientes estudados parece tender a uma menor dominância e maior eqüitabilidade.

3) O uso de armadilhas de intercepção e queda com cerca-guia mostrou-se eficiente na captura de anuros serapilheira e o uso de baldes maiores permitiu uma amostra considerável de espécies do gênero Eleutherodactylus como $E$. binotatus, desconsiderado da análise em trabalhos com baldes menores.

4) A riqueza e abundância das espécies são diferentes entre as estações do ano, sendo maior no verão (primavera + verão) período que coincide com as maiores temperaturas e maior volume de chuva.

5) Os ambientes de floresta nativa apresentam maior diversidade, maior riqueza e maior abundância de indivíduos.

6) B. crucifer e $P$. cuvieri foram as espécies mais abundantes nos plantios de $E$. saligna, comportando-se como espécies generalistas. 


\section{REFERÊNCIAS BIBLIOGRÁFICAS}

ALLMON, W. D. A plot study of forest litter frogs, Central Amazon, Brazil. Journal of Tropical Ecology, v.7, p.503-522, 1991.

ANTUNES, A.P. A fauna de serpentes em área alterada da Serra do Mar, Município de Pilar do Sul, SP. Rio Claro, 2003. 61p. Monografia (Graduação) - Instituto de Biociências, Universidade Estadual Paulista "Julio Mesquita Filho".

BENNET, A.F. Hábitat corridors and the conservation de small mammals in a fragmented forest environment. Landscape Ecology, v.4, p.109-122, 1990.

BERTOLUCI, J.; RODRIGUES, M.T. Utilização de habitats reprodutivos e micro-habitats de vocalização em uma taxocenose de anuros (AMPHIBIA) da Mata Atlântica do sudeste do Brasil. Papéis Avulsos de Zoologia v.42, n.11, p.287-197, 2002.

BLAUSTEIN, A.R.; WAKE, D.B.; SOUSA, W.P. Amphibian declines: judging stability, persistance, and susceptibility of populations to local and global extinctions. Conservation Biology, v.8, p.60-71, 1994.

BRADFORD, D.F.; TABATABAI, F.; GRABER, D.M. Isolation of the native frog, Rana muscosa, by introduced fishes in Sequoia and Kings Canion National parks, California. Conservation Biology, v.7, p.882-888, 1993. 
BRASIL. Ministério Do Meio Ambiente. Diretrizes para a política de conservação e desenvolvimento sustentável da Mata Atlântica. Brasília: s. ed., 1999, caderno n.13. 30p.

BROWN, W.C.; ALCALA, C. Populations of amphibians and reptiles in the submontane and montane forest of Cuernos de Negros, Philippine Islands. Ecology, v.42, p.628-636, 1961.

BROWN Jr., K.S.; BROWN, G.G. Habitat alteration and species loss in Brazilian forests. In: WHITMORE, T.C., SAYER, J.A. (Ed.) Tropical deforestation and species extinction. New York: Chapman and Hall, 1992. cap.6, p.119-142.

CADLE, J.E.; PATTON, J.L. Distribution patterns of some amphibians, reptiles and mammals of the eastern andean and southern Peru. In: VANZOLINI, P.E.; HEYER, W.R. (Ed.) Proceedings of a Workshop on Neotropical Distribution Patterns. Rio de Janeiro: Academia Brasileira de Ciências, 1988. cap.4, p.225-244.

CECHIN, S.Z.; MARTINS, M. Eficiência de armadilhas de queda (pitfall traps) em amostragens de anfíbios e répteis no Brasil. Revista Brasileira de Zoologia, v.17, p.729-740, 2000.

COLWELL, R.K. Programa EstimateS, version 5: Statistical estimation of species richness and shared species from samples. User's Guide and application published at: http://viceroy.eeb.uconn.edu/estimates, 1997. 
CORN, P.S. Straight-Line Drift Fences and Pitfall Traps. In: HEYER, W.R.; DONNELY, M.A.; MCDIARMID, R.W.; HAYEK, L.C.; FOSTER, M.S. (Ed.) Measuring and monitoring Biological Diversity. Standard Methods for Amphibians. Washington; London: Smithsonian Institution Press, 1994. cap.6, p.109-117.

CRUZ, C.A.G.; PEIXOTO, O.L. Espécies verdes de Hyla: o complexo "albosignata" (Amphibia, Anura, Hylidae). Arquivos da Universidade Federal Rural do Rio de Janeiro, v.7, p.31-47. 1948.

DIXO, M.B.O. Efeito da fragmentação da floresta sobre a comunidade de sapos e lagartos de serapilheira no sul da Bahia. São Paulo, 2001. 77p. Dissertação (Mestrado) - Universidade de São Paulo.

DONNELLY, M.A.; GUYER, C.; JUTERBOCK, E.; ALFORD, R.A. Techniques for marking amphibians. In: HEYER, W.R.; DONNELLY, M.A.; MCDIARMID, R.W.; HAYEK, L.C.; FOSTER, M.S. (Ed.), Measuring and monitoring biological diversity: standard methods for amphibians. Washington: Smithsonian Institution Press, 1994. appendix 2, p. 277-284.

DUELLMAN, W. E. Patterns of species diversity in anuran amphibians in the american tropics. Annals of the Missouri Botanical Garden, v.75, p.79104, 1988.

EMPRESA BRASILEIRA DE PESQUISA AGROPECUÁRIA. Atlas do Meio Ambiente do Brasil. Brasília: Terra Viva, 1994. 138p.

FAUTH, J.E.; CROTTHER, B.L.; SLOWINSKI, B. Elevational patterns of richness, evenness, and abundance of the Costa Rican leaf litter herpetofauna. Biotropica, v.21, p.178-185, 1989. 
FONSECA, G.A.B. The vanishing Brazilian Atlantic Forest. Biological Conservation, v.34, p.17-34, 1985.

GASCON, C.; LOVEJOY, T.E.; BIERREGAARD R.O.; MALCOM, J.R.; STOUFFER, P.C.; VASCONCELOS, H.; LAURANCE, W.E.; ZIMMERMAN, B., TOCHER, M.; BORGES, S. Matrix hábitat and species persistence in tropical forest remnants. Biological Conservation, v.91, p.223-229, 1999.

GIARETTA, A.A.; SAWAYA; R.J.; MACHADO; G.; ARAÚJO; M.S.; FACURE; K.G.; MEDEIROS, H.F.; NUNES, R. Diversity and abundance of litter frogs at altitudinal sites at Serra do Japi, Southeastern Brazil. Revista Brasileira de Zoologia, v.14, n.2, p.341-346, 1997.

GIARETTA, A.A. Diversidade e densidade de anuros de serapilheira num gradiente altitudinal na Mata Atlântica costeira. Campinas, 1999. 140p. Tese (Doutorado) - Instituto de Biologia, Universidade Estadual de Campinas.

GIARETTA, A.A.; FACURE, K.G.; SAWAYA, R.J.; MEYER, DE M.; CHEMIN, N. $J$. Diversity and abundance of litter frog in a montane Forest of Southeastern Brazil: seasonal and altitudinal changes. Biotropica, v.31, p.669-674, 1999.

GOTELLI, N.J; COLWELL, R.K. Quantifying biodiversity: procedures and pitfalls in the measurement and comparison de species richness. Ecology Letters, v.4, p.379-391, 2001.

GREENBERG, C.H.; NEARY, D.C.; HARRIS, L.D. A comparison of herpetofaunal sampling effectiveness of pitfall, single-ended, and doubleended funnel traps used with drift fences. Journal of Herpetology, v.28, n.3, p.319-324, 1994. 
GUIX, J.C.; TABANEZ, A.A.J.; SILVA. A.N.; DA LÓPEZ, C.; MARTÍNEZ, C.; MATHEU, E.; SOUZA, F.L.; DE PISCIOTTA, K.R.; BRADBURY, N.; PORTILHO, W.G. Viagem de reconhecimento científico a algumas áreas desconhecidas da Fazenda Intervales, Estado de São Paulo, durante o período de 4 a 16 de outubro de 1991. Grupo de Estudos Ecológicos. Série Documentos, v.4, p.38-94, 1992.

HADDAD, C.F.B. Ecologia reprodutiva de uma comunidade de anfíbios anuros na Serra do Japi, sudeste do Brasil. Campinas, 1991. 156p. Tese (Doutorado) - Instituto de Biociências, Universidade Estadual de Campinas.

HADDAD, C.F.B.; SAZIMA, I. Anfíbios anuros da Serra do Japi. In: MORELLATO, L.P.C. (Org.). História Natural da Serra do Japi: Ecologia e preservação de uma área florestal no Sudeste do Brasil. Campinas: Unicamp/FAPESP, 1992. p.188-210.

HADDAD, C.F.H.; POMBAL JÚNIOR.,J.P.; MATISTIC, R.F. Natural hybridization between diploid and tetraploid species of leaf-frogs, genus Phyllomedusa (Amphibia). Journal of Herpetology, v.28, n.4, p. 425-430, 1994.

HEINEN, J.T. Comparisons of the leaf litter herpetofauna in abandoned cacao plantations and primary rain forest in Costa Rica: some implications for faunal restoration. Biotropica, v. 24, p.43-439, 1992.

HENEIN, K.; MERRIAM, G. The elements of connectivity where corridor quality is variable. Landscape Ecology, v. 4, p.157-170, 1990.

HEYER, W.R. A herpetofaunal study of an ecological transect through the Cordillera de Tilaran, Costa Rica. Copeia, v.1967, n.2, p.259-271, 1967. 
HEYER, W.R. On frog distribution patterns east of the Andes. In: VANZOLINI, P.E.; HEYER, W.R. (Ed.) Proceedings of a Workshop on neotropical distribution patterns. Rio de Janeiro: Academia Brasileira de Ciências, 1988. cap.5, p. 245-273.

HEYER, W.R.; BERVEN, K.A. Species diversities of herpetofauna samples from similar microhábitats at two tropical sites. Ecology, v.54, p.642-645, 1973.

HEYER, W.R.; RAND, A.S.; CRUZ, C.A.G.; PEIXOTO, O.L.; NELSON, C.E. Frogs of Boracéia. Arquivos de Zoologia, v. 31, n.4, p.231-410, 1990.

HURLBERT, H.S. The nonconcept of species diversity: a critique and alternative parameters. Ecology, v.52, p.577-586, 1971.

INGER, R.F. Relative abundances of frogs and lizards in forests of Southeast Asia. Biotropica, v.12, p.14-22, 1980a.

INGER, R.F. Densities of floor-dwelling frogs and lizards in lowland forest of Southeast Asia and Central America. American Naturalist, v.115, p.761770, 1980(b).

JANZEN, D.H. Sweep samples of tropical foliage insects: Description of study sites, with data on species abundances and size distributions. Ecology, v.54, p.659-686, 1973.

KLEEBERGER, S.R.; WERNER, J.K. Home range and homing behavior of Plethodon cinereus in northern Michigan. Copeia, v.1982, p. 409-415, 1982. 
KOVACH, W.L. Programa MVSP, version 3.1: A Multivariate Statisticat Package for windows (software). U.K., Pentraeth, Wales: Kovach Computing services, 1999. 133p.

KREBS, C.J. Ecological Methodology. New York: Harper and Row, 1989. $654 p$.

KREBS, C.J. Ecological Methodology. 2.ed. New York: Addilson-WeLsey Educational Publishers, 1998. 581p.

KWET, A.; DI-BERNARDO, M. Anfíbios=amphibien=amphibians. Porto Alegre: EDIPUCRIS, 1999. 170p.

LAURANCE, W.F. Ecological correlates of extinction proneness in Australian tropical rain forest mammals. Conservation Biology, v. 5, p.79-89, 1991a.

LAURANCE, W.F.; GASCON, C. How to creatively fragment landscape. Conservation Biology, v.11, p.577-579, 1997.

LAURANCE, W.F.; BIERREGAARD, R.O. Tropical Forest Remnant. Ecology, management, and conservation of fragmented communities. Chicago: Univ. Chicago Press, 1997. 616 p.

LEITÃO FILHO, S.H.F. Aspectos taxonômicos das florestas do Estado de São Paulo. In: CONGRESSO NACIONAL DE ESSÊNCIAS NATIVAS, São Paulo, 1982. Silvicultura em São Paulo, v.1, p.197-206.

LIMA, M.G.; GASCON, C. The conservation value of linear forest remnants in central Amazonia. Biological Conservation, v.91, p.241-247, 1999. 
LLOYD, M.; INGER, R.F.; KING, F.W. On the diversity of reptile and amphibian species in a Bornean rain forest. American Naturalist, v.102, p.497-515, 1968.

MACARTHUR, R.H.; WILSON, E.O. The theory of island biogeography. New Jersey: Princeton University Press, 1967. 203p.

MAGURRAN, A.E. Ecological diversity and its measurements. New Jersey: Princeton University Press, 1988. 179p.

MANLY, B.F.J. Randomization, Bootstrap and Monte Carlo Methods in Biology. London: Chapman and Hall, 1991. 281p.

MARTINS, M.R.C. História natural e ecologia de uma taxocenose de serpentes de mata na região de Manaus, Amazônia Central, Brasil. Campinas, 1994. 98p. Tese (Doutorado) - Instituto de Biologia, Universidade Estadual de Campinas.

MAY, R.M. Patterns of species abundance and diversity. In: CODY, M.L.; DIAMOND, J.M. (Ed.) Ecology and Evolution of Communities. Cambridge, Mass : Belknap Press of Harvard University, 1982. p. 81-120.

MCCUNE, B.; MEFFORD, M.J. Programa PC-ORD, version 3.15 MJM: Multivariate analysis of ecological data (software). Oregon: Gleneden Beach, 1997. 237p.

MEFFE, G.K.; CARROL, C.R. What is conservation biology? In: MEIFE, G.K.; CARROL, C.R. (Ed.) Principles of Conservation Biology. Sunderland, Massachusetts: Sinauer Associates Press, 1994. cap.1, p.3-23. 
MELO, A.S.; PEREIRA; R.A.S.A.; SANTOS; J.; SHEPHERD; G.J.; MACHADO; G.; MEDEIROS, H.F.; SAWAYA, R.J. Comparing species richness among assemblages using sample units: Why not use extrapolation methods to standardize different sample sizes? Oikos, v.101, p.398-410, 2003.

METZGER, J.P.; DÉCAMPS, H. The structure connectivity threshold: an hypothesis in conservation biology at the landscape scale. Acta Ecologica, v.18, p.1-12, 1997.

MIRANDA, E.E.; MATTOS, O. Brazilian rain forest colonization and biodiversity. Agricultural Ecosystems and Environnmental, v.40, p.275-296, 1992.

MORELLATO, L.P.; HADDAD, C.F.B. Special issue: The Brazilian Atlantic Forest. Biotropica, v.32, n.4b, p.786-792, 2000.

NOSS, R.F. Corridors in real landscape: reply to Simberloff and Cox. Conservation Biology, v.1, p.159-164, 1987.

NOSS, R.F.; CSUTI, B. Hábitat Fragmentation. In: MEIFE, G.K.; CARROL, C.R. (Ed.) Principles of Conservation Biology. Sunderland, Massachusetts: Sinauer Associates Press, 1994. cap.9, p.237-264.

OLIVEIRA-FILHO, A.; FONTES, M.A.L. Patterns of floristic differentiation among Atlantic Forest of southeastern Brazil, and the influence of climate. Biotropica, v.32, p.793-810, 2000. 
PIRES, A.M.Z.C. Elaboração de um banco de dados digitais georeferenciados como subsídio ao planejamento e manejo de uma Unidade de conservação Estação Ecológica de Jataí (Luiz Antônio, São Paulo). São Carlos, 1995. 179p. Tese (Doutorado) - Centro de Ciência Biológicas e da Saúde, Universidade Federal de São Carlos.

POMBAL JÚNIOR, J.P. Biologia Reprodutiva de anuros (Amphibia) associados a uma poça permanente na Serra de Paranapiacaba, sudeste do Brasil. Rio Claro, 1995. 163p. Tese (Doutorado) - Instituto de Biociências, Universidade Estadual Paulista "Júlio Mesquita Filho".

RÖHE, F. Hábitos alimentares da suçuarana (Puma concolor) (Lineus, 1771) em mosaico de floresta secundária e reflorestamento de E. saligna, em Mata Atlântica, no Município de Pilar do Sul - SP. Rio Claro, 2002. 76p. Monografia (Graduação) - Faculdade de Ecologia, Universidade Estadual Paulista "Júlio de Mesquita Filho".

SAUNDERS, D.A.; HOBBS, R.J.; MARGULES, C.R. Biological consequences of ecosystem fragmentation: a review. Conservation Biology, v.7, p.18-32, 1991.

SAWAYA, R.J. Diversidade, densidade e distribuição altitudinal da anurofauna de serapilheira da llha de São Sebastião, SP. São Paulo, 1999. 65p. Dissertação (M.S.) - Instituto de Biociências, Universidade de São Paulo.

SCOTT, N.J.,Jr. The abundance and diversity of the herpetofaunas of tropical forest litter. Biotropoica, v.8, p.41-58, 1976.

SHAFER, C.L. Nature Reserves: Island theory and conservation practice. Washington: Smithsonian Institution Press, 1990. 189 p. 
SILVA, C.R. Riqueza e diversidade de mamíferos não voadores em um mosaico formado por plantios de Eucalyptus saligna e remanescentes de Floresta atlântica no Município de Pilar do Sul, SP. Piracicaba, 2001. 81p. Dissertação (Mestrado) - Escola Superior de Agricultura "Luiz de Queiroz", Universidade de São Paulo.

$\mathrm{SINCH}, \mathrm{U}$. Migration and orientation in anuran amphibians. Ethology, Ecology \& Evolution, v.2, p.65-79, 1990.

SOS. MATA ATLÂNTICA. Boletim informativo, jun./jul. v.1, n.8, 1999.

STALLINGS, J.R. Small mammal inventories in an Eastern Brazilian Park. Bulletin Florida State Museum, Biological Scientific, v.34, n.4, p.153-200, 1989.

STALLINGS, J.R. The importance of understorey on wildlife in a Brazilian eucalipt plantation. Revista Brasileira de Zoologia, v.7, p.267-276, 1991.

TAYLOR, P.D.; FAHRIG, L.; HENEINJ K.; MERRIAN, G. Connectivity is a vital element of landscape structure. Oikos, v.55, p.121-1 29, 1993.

TERBORGH, J. Maintenance of diversity in tropical forests. Biotropica, v.24, n.2, p.283-292, 1992.

TOCHER, M.D.; GASCON, C.; ZIMMERMAN, B.L. Fragmentation effects on a Central Amazonian frog community: a ten year study. In: LAURANCE, W.F.; BIERGAARD, R.O. (Ed.). Tropical Forest Remnants: Ecology, Management, and Conservation of Fragmented Communities. Chicago: University of Chicago Press, 1997. cap. 9, p.124-155. 
TURNER, I.M. Species loss in fragments of tropical rain forest: a review of the evidence. Journal Applied Ecology, v.33, p.200-209, 1996.

TURNER, I.M.; CORLETT, R.T. The conservation value of small, isolated fragments of lowland tropical ram forest. Tree, v.11, n.8, p.330-333, 1996.

VELOSO, H.P. Classificação da vegetação brasileira, adaptada a um sistema universal. Rio de Janeiro: IBGE, Departamento de Recursos Naturais e Estudos Ambientais, 1991. 72 p.

VITT, L.J.; CALDWELL, J.P. Resource utilization and guild structure of small vertebrates in the Amazon forest leaf litter. Journal of Zoology, v.234, p.463-476, 1994.

WAKE, D.B. Declining amphibian populations. Science, v. 253, p.860, 1991.

WEBB, G.A. Effectiveness of pitfall/drift-fence systems for sampling small ground-dwelling lizards and frogs in southeastern Australian forests. Australian Zoologist, v.31, n.1, p.118-126, 1999.

WILCOX, B.A.; MURPHY, D.D. Conservation strategy: the effects of fragmentation on extinction. American Naturalist, v.125, p.879-887, 1985.

WILSON, E.O. Estrategia de conservación de la biodiversidad. In: WRI/UICN/PNUMA. Estrategia Global para la Biodiversidad Pautas de Acción para Salvar, Estudiar y Usar en Forma Sostenible y Equitativa la Riqueza Biótica de la Terra. s.l., 1992. 243 p.

WYMAN, R.L. What is happening to the amphibians? Conservation Biology, v.4, p.350-352, 1990. 
ZIMMERMAN, B.L., BIERREGAARD, R.O., Jr. Relevance of the equilibrium theory of island biogeography and species-area relations to conservation with a case from Amazonia. Journal of Biogeography, v.13, p.133-143, 1986.

ZIMMERMAN, B.L.; BOGART, J.P. Ecology and calls species of Amazonian Forest frogs. Journal of Herpetology, v.22, n.1, p.97-108, 1988.

ZIMMERMANN, B.L.; RODRIGUES, M.T. Frogs, Snakes, and Ljzards of the INPA/WWF reserves near Manaus, Brazil. In: GENTRY, A.H. (Ed.) Four Neotropical Rainforests. New Haven: Yale University Press, 1990. cap.23, p.426-454. 